\title{
Effect of High-temperature on the Swellable Organically-Modified Silica (SOMS) and Its Application to Gas-Phase Hydrodechlorination of Trichloroethylene
}

Hyuntae Sohn ${ }^{1}$, Gokhan Celik ${ }^{1}$, Seval Gunduz ${ }^{1}$, Sreshtha Sinha Majumdar ${ }^{1}$, Stacey L. Dean ${ }^{2}$, Paul L. Edmiston ${ }^{2,3, * *}$ and Umit S. Ozkan ${ }^{1, *}$ 


\begin{abstract}
Pd catalysts supported on swellable organically-modified silica (SOMS) and high-temperaturetreated swellable organically-modified silica (H-SOMS) were characterized and tested for gasphase hydrodechlorination (HDC) of trichloroethylene (TCE) conditions. The high-temperature treatment on SOMS resulted in an increase in surface area and pore diameter as well as significant improvement of Pd dispersion on H-SOMS with smaller Pd particle sizes compared to the $\mathrm{Pd} / \mathrm{SOMS}$ catalyst. Although the high-temperature treatment led to some alteration of the SOMS polysiloxane network, the hydrophobicity and organic vapor adsorption characteristics of SOMS were preserved. The reduction and oxidation characteristics of Pd on SOMS and HSOMS were investigated in situ using XANES technique. It was found that the Pd sites in the pores of SOMS was accessible to small molecules such as $\mathrm{H}_{2}$, facilitating the reduction of $\mathrm{PdO}_{\mathrm{x}}$, whereas oxidation of metallic Pd was limited even at higher temperatures when $\mathrm{O}_{2}$ was used. This effect was only observed over Pd/SOMS catalyst. For Pd/H-SOMS, because the pores were more widely open than $\mathrm{Pd} / \mathrm{SOMS}$, both reduction and oxidation of $\mathrm{Pd}$ were observed. Finally, the catalytic activity of $\mathrm{Pd} / \mathrm{H}-\mathrm{SOMS}$ for gas-phase HDC of TCE was significantly better than $\mathrm{Pd} / \mathrm{SOMS}$. When water was added to the reactant stream $\left(\mathrm{TCE}+\mathrm{H}_{2} \mathrm{O}\right)$, both $\mathrm{Pd} / \mathrm{SOMS}$ and $\mathrm{Pd} / \mathrm{H}-$ SOMS maintained its catalytic performances due to hydrophobic property of the supports.
\end{abstract}

Keywords: organically-modified silica (SOMS), hydrodechlorination (HDC), trichloroethylene 


\section{Introduction}

Trichloroethylene (TCE) has been widely used for metal degreasing processes in the U.S industry. ${ }^{1-2}$ However, due to its toxicity as a carcinogen, ${ }^{3-4}$ a proper treatment should be performed before releasing it to the environment. Recently, TCE has been reported as one of the most widely found volatile organic compound contaminants in groundwater, ${ }^{5-6}$ which, is a major source for human drinking water. The toxicological profile for TCE published by U.S. Department of Health and Human Services reports that TCE was detected in 4.5 to $18 \%$ of the drinking water sources in United States with less than $30 \mathrm{ppb}^{7}$ Currently, the MCL (maximum contaminant level) set by the U.S. Environmental Protection Agency (EPA) is 5 ppb for TCE.

The most widely used groundwater remediation technologies includeair stripping, ${ }^{8-9}$ air sparging $^{10}$ and soil venting ${ }^{11}$ that are pump-and-treat process. However, these methods only transfer TCE from liquid to gas phase, which then require a secondary vapor treatment system. This is usually done using adsorbents such as GAC (granular activated carbon) followed by an oxidation process or incinerator that produce carbon dioxide and toxins from incomplete combustion. ${ }^{8,11-13}$ The high operating temperature is also not economically favorable. Thus, insitu groundwater remediation methods such as bioremediation ${ }^{14}$ and chemical oxidation ${ }^{15-16}$ have been widely studied to eliminate TCE from groundwater. An alternative technique is catalytic hydrodechlorination (HDC) of TCE which is the focus of this study. The use of metal-based catalyst converts TCE into ethane and hydrogen chloride $(\mathrm{HCl})$. The process can be implemented for both in-situ groundwater remediation and gas phase TCE vapor treatment systems. 
With respect to catalysts, noble metals have been tested and shown promising catalytic activity. ${ }^{17-19}$ Ordóñez et al. examined eight commercial catalysts for HDC of TCE at reaction conditions of $300{ }^{\circ} \mathrm{C}$ and 50 bar in liquid phase. ${ }^{17}$ It was found that over Pt, Pd and Ru based catalysts, high TCE conversions were obtained. In the literature, Pd metal has been the most studied catalyst for HDC of TCE. ${ }^{20-27}$ For example, Pd supported on different types of catalyst supports have been investigated including $\mathrm{Al}_{2} \mathrm{O}_{3},{ }^{20}$ activated carbon $(\mathrm{AC}),{ }^{17} \mathrm{MCM}-41^{28}$ and ZSM-5 zeolites. $^{29}$ Lowry and coworkers have reported promising catalytic performance of $\mathrm{Pd} / \mathrm{Al}_{2} \mathrm{O}_{3}$ obtaining TCE conversion of $97 \%$ at ambient pressure and temperature in liquid phase. $^{30} \mathrm{Yu}$ et al. demonstrated TCE conversions achieved over six different Pd catalysts supported on MCM-41, $\mathrm{P}_{25}, \mathrm{SiO}_{2}, \mathrm{HAP}, \mathrm{NiO}$ and $\mathrm{MgO}$ under HDC of TCE conditions using formic acid instead of hydrogen gas. ${ }^{28}$ The highest catalytic activity was obtained over Pd/MCM41. In addition, bimetallic catalysts were employed and tested for HDC of TCE. Wong and coworkers reported a significantly higher catalytic performance using $\mathrm{Pd} / \mathrm{Au}$ nanoparticles compared to $\mathrm{Pd} / \mathrm{Al}_{2} \mathrm{O}_{3} \cdot{ }^{24,31}$ Modification of the catalyst properties by adding $\mathrm{Pd}$ capping agents such as carboxymethyl cellulose (CMC $)^{22,32-33}$ and coating Pd metals with poly(dimethylsiloxane) $(\mathrm{PDMS})^{34-36}$ have been researched and shown high activities.

Non-noble metals such as zero valent iron (ZVI) have also been widely studied. ${ }^{37-40}$ ZVI acts as a reducing agent in the presence of water, thus producing hydrogen gas for HDC reactions. ${ }^{41}$ Lin and coworkers stated that among $\mathrm{Pd} / \mathrm{Fe}, \mathrm{Pt} / \mathrm{Fe}, \mathrm{Ru} / \mathrm{Fe}$ and $\mathrm{Au} / \mathrm{Fe}$ catalysts with $0.25 \%$ metal loading where $0.25 \% \mathrm{Pd} / \mathrm{Fe}$ exhibited the highest catalytic performance of all for aqueous phase HDC of TCE in the absence of hydrogen gas. ${ }^{42}$ It was found that the production of hydrogen from water was considerably greater over $\mathrm{Pd} / \mathrm{Fe}$ compared to others. To further decrease the cost 
of the catalyst, $\mathrm{Ni} / \mathrm{Fe}$ has been used as an alternative to $\mathrm{Pd} / \mathrm{Fe} .^{41,43}$ More recently, molybdenum phosphide (MoP) was investigated for HDC of TCE reaction. ${ }^{44-45}$

Gas phase HDC of TCE can be used to treat TCE vapors from large-scale plants where incinerator or chemical oxidation processes are normally utilized. ${ }^{46}$ The concentration of TCE vapors especially in degreasing industry ranges from 1 to $100 \mathrm{ppm} .^{7}$ In the literature, the reaction is performed at relatively higher temperatures and has been the focus of fewer studies compared to those in the liquid-phase. ${ }^{19,47-48}$ Meshesha et al. reported $80 \%$ ethylene selectivity from HDC of TCE using Pd/NiMgAl mixed oxide catalyst at $573 \mathrm{~K}$ in a fixed bed reactor. ${ }^{48}$ Finocchio and coworkers $^{46}$ tested several metal-free catalysts to treat TCE vapor in humid and dry reaction conditions. They obtained complete conversion of TCE over $\gamma$-alumina at temperature of $820 \mathrm{~K}$.

Previously, we have reported on a new class of materials, swellable organically-modified silica (SOMS), as catalyst support for Pd used in HDC of TCE. ${ }^{49}$ SOMS is an extremely hydrophobic and adsorptive material, which can adsorb various types of organic compounds from air and water. When sufficient adsorption takes place, pore filling can initiate the physical expansion of the SOMS volume, called as "swelling". The increase in volume comes with an increase in pore volume and surface area. ${ }^{50}$ The swelling mechanism is reversible, thus, when the adsorbed molecules are liberated from SOMS, the physical volume of SOMS returns to its original size. Steady-state liquid phase reaction experiments showed a higher activity and stability for $\mathrm{Pd} / \mathrm{SOMS}$ catalysts compared to commercial $\mathrm{Pd} / \mathrm{Al}_{2} \mathrm{O}_{3}$ catalysts. The higher catalytic activity over Pd/SOMS was attributed to the swelling behavior of SOMS, which only adsorbed TCE molecules from the solution (hydrophobicity) and concentrated them in the vicinity of the Pd active sites inside the pores. ${ }^{49}$ Additionally, the $\mathrm{Pd}$ active sites were protected by the strong 
hydrophobicity of SOMS from poisoning by sulfur anions dissolved in water. ${ }^{49}$ It was observed that the $\mathrm{Li}_{2} \mathrm{~S}$ poisoned-1\% $\mathrm{Pd} / \mathrm{SOMS}$ maintained its catalytic activity compared to fresh $1 \%$ $\mathrm{Pd} / \mathrm{SOMS}$ whereas $\mathrm{Li}_{2} \mathrm{~S}$ poisoned- $1 \% \mathrm{Pd} / \mathrm{Al}_{2} \mathrm{O}_{3}$ catalyst was completely deactivated. Also, $\mathrm{Pd}$ supported on SOMS was seen to be more resistant to leaching in acidic medium. ${ }^{49}$ When both $\mathrm{Pd} / \mathrm{SOMS}$ and $\mathrm{Pd} / \mathrm{Al}_{2} \mathrm{O}_{3}$ were treated with $\mathrm{HCl}$, most of the Pd particle were leached out from the $\mathrm{Al}_{2} \mathrm{O}_{3}$ support while $\mathrm{Pd}$ particles were still present on the SOMS. Kopinke et al. reported similar results using silicone polymer coated $\mathrm{Pd} / \mathrm{Al}_{2} \mathrm{O}_{3}$ catalysts where hydrophobicity of the material facilitated better protection of the Pd active sites from ionic poisoning sources such as bisulphite for $24 \mathrm{~h}^{35}$

Although Pd/SOMS showed promising activity in the liquid phase, in the gas phase, the activity was much lower than that of $\mathrm{Pd} / \mathrm{Al}_{2} \mathrm{O}_{3}$. This was attributed to the fact that in the gas phase, the SOMS matrix adsorbs less total mass of TCE than in aqueous solution where adsorption of the TCE from water into by the hydrophobic pore structure is favored. In the gas phase, the swollen state is not achieved, making the active sites inside the pores inaccessible.

In this article, we report the use of SOMS treated at high temperatures under an inert environment (H-SOMS) prior to the Pd impregnation step. This treatment was to improve Pd accessibility of SOMS for the gas-phase HDC of TCE. The evolution of SOMS during hightemperature treatment was examined using temperature programmed decomposition (TPD) technique. ${ }^{29} \mathrm{Si}$ Nuclear magnetic resonance (NMR) and Infrared (IR) Spectroscopy techniques were used to understand the chemical structure of H-SOMS. High Angle Annular Dark Field (HAADF) Scanning Transmission Electron Microscopy (STEM) and CO chemisorption methods were employed to obtain particle size and Pd dispersion. The change in Pd oxidation state during 
reduction and oxidation process were followed using in-situ X-ray Absorption Near Edge Structure (XANES) Spectroscopy. Lastly, gas-phase HDC of TCE was conducted at 100, 150 and $200{ }^{\circ} \mathrm{C}$ to acquire TCE and HDC conversion and product distribution. All the characterization techniques and activity testing were also performed over regular Pd/SOMS for comparison.

\section{Experimental}

\subsection{Catalyst Preparation}

A detailed sol-gel synthesis method to prepare SOMS was reported by Edmiston and coworkers. ${ }^{50-54}$ The first step involved mixing two solutions, bis(trimethoxysilylethyl) benzene (BTEB) dissolved in acetone and tetrabutylammonium fluoride dissolved water. Mixing the two solutions initiated gelation and the resulting gel was kept at $25^{\circ} \mathrm{C}$ for 6 days. The gel was then rinsed with acetone, ground and derivatized using $5 \mathrm{v} / \mathrm{v} \%$ solution of chlorotrimethylsilane in acetonitrile for $24 \mathrm{~h}$. Finally, the solution was filtered and the remaining solids were washed with acetone and dried at $110{ }^{\circ} \mathrm{C}$ to obtain SOMS, as a white color solid.

The high-temperature treated SOMS, referred to as H-SOMS in this paper, was prepared by calcining SOMS under inert conditions. The SOMS was first saturated with acetone until no more volume expansion was observed (fully swollen). This was to increase the surface area and pore volume of the SOMS to its swollen state before the calcination was carried out. The saturated SOMS was placed into a horizontal quartz tube which was flushed with nitrogen for 5 min to remove oxygen inside. The quartz tube was then transferred into the center of a heated 
furnace at $600{ }^{\circ} \mathrm{C}$ while nitrogen was flowing through the tube. SOMS was calcined for $2 \mathrm{~h}$ under a nitrogen flow. Afterwards, the calcined SOMS, i.e. H-SOMS, was obtained as a browncolored solid.

Incipient wetness impregnation (IWI) technique was used to create Pd particles within the SOMS support. A known amount of Pd acetate solid (1\% wt Pd relative to the support) was dissolved in sufficient acetone to achieve a solution and aid the swelling process. These precursors were chosen to allow the opening of the pores during impregnation. The Pd precursor solution was then added drop-wise until SOMS was saturated. The Pd impregnated SOMS was then dried at RT with constant agitation. The entire process was repeated multiple times to use all of the precursor solution. The $1 \% \mathrm{Pd} / \mathrm{SOMS}$ was obtained after the final drying step. For H-SOMS, similar preparation steps were employed, except that the solids were dried at $100{ }^{\circ} \mathrm{C}$. The $\mathrm{Pd} / \mathrm{SOMS}$ was dried at RT to make sure that the sample did not go through a thermal treatment.

The reduction of $\mathrm{Pd}\left(\mathrm{Pd}^{2+}\right.$ to $\left.\mathrm{Pd}^{0}\right)$ was carried out chemically using a saturated solution of $\mathrm{NaBH}_{4}$ in $95 \%$ ethanol in the case of $1 \% \mathrm{Pd} / \mathrm{SOMS}$. After $\mathrm{Pd} / \mathrm{SOMS}$ was soaked in the $\mathrm{NaBH}_{4}$ solution, it was filtered and rinsed with ethanol followed by deionized water. The remaining solids were dried at $60{ }^{\circ} \mathrm{C}$. For the reduction of $1 \% \mathrm{Pd} / \mathrm{H}-\mathrm{SOMS}, 5 \% \mathrm{H}_{2} / \mathrm{He}$ gas was utilized at which the catalyst was reduced in-situ at $400{ }^{\circ} \mathrm{C}$ for $1 \mathrm{~h}$. The reduced Pd/H-SOMS was then treated with helium at $450{ }^{\circ} \mathrm{C}$ for $30 \mathrm{~min}$ for surface clean-up. The reason for using two different prereduction treatments was due to thermal decomposition of SOMS. As reported in the TPD results (Section 3.1) SOMS started to decompose around $400{ }^{\circ} \mathrm{C}$. Therefore, if $\mathrm{Pd} / \mathrm{SOMS}$ was prereduced using the hydrogen at $400{ }^{\circ} \mathrm{C}$, chemical properties of SOMS would change. Thus, an alternative way was implemented $\left(\mathrm{NaBH}_{4}\right)$ which can be conducted at $25^{\circ} \mathrm{C}$. 


\subsection{Catalyst Characterization}

\subsubsection{Temperature Programmed Decomposition (TPD)}

TPD experiment was performed using a Carbolite MTF 10/15/130 furnace where a 4 mm-ID quartz reactor was located at the center of the furnace. SOMS was first placed inside the quartz reactor supported by quartz wool plugs. A continuous flow of pure helium was then introduced to the reactor at $30 \mathrm{ml} / \mathrm{min}$ at $\mathrm{RT}$ and the effluent was sent to a mass spectrometer (MS - MKSCirrus II) operated in scanning ion mode. Once a stable MS signal of helium was obtained, the furnace temperature was increased gradually at a ramp rate of $10{ }^{\circ} \mathrm{C} / \mathrm{min}$ from $\mathrm{RT}$ to $800{ }^{\circ} \mathrm{C}$ and stayed there for $150 \mathrm{~min}$. For identification of the products, signals from $\mathrm{m} / \mathrm{z}=2$ to 60 were monitored.

\subsubsection{Surface Area, Pore Size and Pore Volume}

Brunauer-Emmet-Teller (BET) surface area and Brunauer-Joyner-Helena (BJH) pore volumes of SOMS, H-SOMS, Pd/SOMS and Pd/H-SOMS were measured using Micromeritics ASAP 2020 (accelerated surface area and porosimetry) instrument. The samples were first degassed for $12 \mathrm{~h}$ at $130{ }^{\circ} \mathrm{C}$ under $2 \mu \mathrm{m} \mathrm{Hg}$ of vacuum and transferred to the analysis port to obtain nitrogen adsorption/desorption isotherms of the samples. The analysis was conducted at liquid nitrogen temperature and the saturation pressure of nitrogen was measured frequently to improve accuracy of the relative pressure calculation. The BJH pore size distribution was acquired using the desorption branch of the isotherm. 


\subsubsection{High Angle Annular Dark Field (HAADF) Scanning Transmission Electron Microscopy}

(STEM)

Identification and particle size information of $\mathrm{Pd}$ were obtained by taking HAADF-STEM images. A small amount of Pd/SOMS and Pd/H-SOMS was first dispersed in ethanol and stirred rigorously for 5 min using a sonicator. The resulting solution was then placed drop-wise on a Tedpella, Inc. 200 mesh copper grid coated with lacey carbon sample holder. After a drying step at RT for $1 \mathrm{~h}$, the sample holder was transferred to FEI Tecnai F20 instrument equipped with a high brightness field emission electron gun (FEG) operated at $200 \mathrm{kV}$ and a HAADF detector. Multiple images were taken in different spots of the TEM grid to ensure uniformity of the Pd particle sizes.

\subsection{4 ${ }^{29}$ Si Nuclear Magnetic Resonance (NMR) and Infrared (IR) Spectroscopy}

${ }^{29}$ Si MAS (Magic Angle Spinning) NMR spectra were collected over Pd/SOMS and Pd/H-SOMS samples using Bruker DPX $300 \mathrm{MHz}$ NMR instrument at a resonance frequency of $59.6 \mathrm{MHz}$. Tetramethylsilane (TMS) was used as a reference for 0 ppm. SpinWorks 4.2.3.0 @2016 software was utilized for line broadening of the spectra. Infrared spectra of SOMS and H-SOMS were acquired using a Thermo Nicolet 6700 FTIR Spectrometer with a diamond attenuated total reflectance (ATR) accessory. The material was ground to a particle size $<250 \mu \mathrm{m}$. Spectra were acquired at $4 \mathrm{~cm}^{-1}$ resolution averaging 16 scans.

\subsubsection{Static Vapor-Phase Adsorption}

Pyris 1 Perkin-Elmer thermogravimetric analyzer (TGA) was used to obtain acetone adsorption profiles of the $\mathrm{Pd} / \mathrm{SOMS}$ and $\mathrm{Pd} / \mathrm{H}-\mathrm{SOMS}$ catalysts at $T=25^{\circ} \mathrm{C}$. The sample was placed inside a 
sealed container in which a saturated acetone vapor was introduced. The mass of the sample was first measured at $0 \mathrm{~s}$ and collected continuously every $6 \mathrm{~s}$ until no further mass increase was observed. Percentage increase in mass $(\%)$ was calculated for each sample.

\subsubsection{CO Chemisorption}

Carbon monoxide $(\mathrm{CO})$ was used as a probe molecule in order to obtain the dispersion of $\mathrm{Pd}$ particles on SOMS and H-SOMS supports. A similar reactor system used for the TPD experiment was employed with an addition of a 6-port valve which allowed introduction of CO gas in pulses. The samples were pre-reduced prior to $\mathrm{CO}$ chemisorption. $\mathrm{Pd} / \mathrm{SOMS}$ was reduced chemically using $\mathrm{NaBH}_{4}$ solution while $\mathrm{Pd} / \mathrm{H}$-SOMS was pre-reduced in-situ under $5 \% \mathrm{H}_{2} / \mathrm{He}$ at $400{ }^{\circ} \mathrm{C}$. The $\mathrm{CO}$ chemisorption experiments were conducted at RT sending known amounts of $\mathrm{CO}$ to the catalyst bed in pulses until saturation was reached. The outlet of the reactor was connected to a MS and the amount of $\mathrm{CO}$ uptake at each pulse was quantified based on the feed (250 $\mu 1$ sample loop) which was calibrated before the reaction. The Pd dispersion was calculated as "number of moles of $\mathrm{Pd}$ reacted with $\mathrm{CO} /$ number of moles of $\mathrm{Pd}$ in the sample". The calculation was performed assuming a 1:1 ratio of Pd to CO.

\subsubsection{In Situ X-ray Absorption Near Edge Structure (XANES) Spectroscopy}

In situ XANES spectra were collected at the insertion device (Sector 10-ID) beamline of the Materials Research Collaborative Access Team (MRCAT) located at the Advanced Photon Source (APS) - Argonne National Laboratory. The measurements were performed in transmission mode using a $\mathrm{Si}$ (111) monochromator with a harmonic rejection mirror covered with $\mathrm{Pt}$ and $\mathrm{Rh}$. The $1 \% \mathrm{Pd} / \mathrm{SOMS}$ and $1 \% \mathrm{Pd} / \mathrm{H}-\mathrm{SOMS}$ samples were first finely ground with/without addition of silica as a diluent to obtain a proper Pd K edge (24.36 KeV) jump. The 
prepared samples were then pressed gently into a six-well sample holder made of stainless steel which was inserted horizontally to a $45 \mathrm{~cm}$ long quartz tube $(2 \mathrm{~cm} \mathrm{ID)}$. The inlet and outlet of the quartz tube were connected to stainless steel tubing fitted with Swagelok fittings to allow in-situ experiments.

All the samples went through the same treatment conditions as follows: (1) helium treatment at RT (2) oxidation at $250{ }^{\circ} \mathrm{C}$, (3) reduction at 150 and $250{ }^{\circ} \mathrm{C}$, (4) re-oxidation at 150 and $250{ }^{\circ} \mathrm{C}$. The sample was kept at each temperature for 30 min which corresponds to $3 \mathrm{~h}$ of experiment time. The gases used for oxidation and reduction were $5 \% \mathrm{O}_{2} / \mathrm{He}$ and $3.6 \% \mathrm{H}_{2} / \mathrm{He}$, respectively. The switch between gases was made after the existing gas in the lines was flushed with helium. Lastly, the quantification of Pd oxidation states was obtained using WinXAS software by linear combination between the spectra of Pd metal foil and PdO standard.

\subsection{Catalyst Activity Testing}

Gas-phase HDC of TCE was performed over 1\% Pd/SOMS and 1\% Pd/H-SOMS catalysts in a bench-scale fixed bed flow reactor system. A nitrogen stream was saturated with TCE using a bubbler at $35^{\circ} \mathrm{C}$. The $\mathrm{N}_{2}$ stream saturated with TCE was then diluted with additional nitrogen in order to lower the concentration of TCE. Afterwards, hydrogen was added to the mixture resulting in a feed composition of $0.7 \%$ (by volume) TCE in excess hydrogen at a TCE-tohydrogen molar ratio of 1:30. For HDC of TCE experiments in the presence of water vapor, the water concentration in the feed was $4 \%$. The reactants were then sent to the catalyst bed located inside the $4 \mathrm{~mm}$-ID quartz reactor. $50 \mathrm{mg}$ of catalyst was used with a $30 \mathrm{ml} / \mathrm{min}$ of total reactant flow. The catalyst bed height was $6 \mathrm{~mm}$. The gas hourly space velocity was obtained as $24000 \mathrm{~h}^{-}$ 
1. The gas-phase HDC of reaction was carried out at 100,150 and $200{ }^{\circ} \mathrm{C}$. The reactor temperature was increased/decreased by an Omega CSC232 PID temperature controller which adjusts the temperature of the surrounding furnace (Carbolite, MTF 10/15/130). All the catalysts were pre-reduced prior to the reaction $\left(\mathrm{Pd} / \mathrm{SOMS}-\mathrm{NaBH}_{4}\right.$ and $\mathrm{Pd} / \mathrm{H}-\mathrm{SOMS}$ - in situ $\left.\mathrm{H}_{2}\right)$. For accurate comparison, the catalytic activities of the samples were obtained at equal gas hour space velocity (GHSV). The feed and the reactor effluent were analyzed using an online gas chromatograph (Shimadzu Scientific 2010) with a Q-bond column and a flame ionization detector (FID). The oven temperature, injector pressure/linear velocity of the He carrier gas were altered to obtain proper separation of the product peaks including TCE, partially dechlorinated compounds, short-chain hydrocarbons, especially the major product ethane.

\section{Results and Discussion}

\subsection{Temperature-programmed decomposition over SOMS}

The procedure for the preparation for H-SOMS was developed after observing the results of a temperature-programmed decomposition (TPD) experiment conducted under helium environment to identify the species that were evolved. Figure 1 shows the profiles for different mass-to-charge ratios $(\mathrm{m} / \mathrm{z})$ of $2\left(\mathrm{H}_{2}\right), 15\left(\mathrm{CH}_{4}\right), 18\left(\mathrm{H}_{2} \mathrm{O}\right), 28\left(\mathrm{C}_{2} \mathrm{H}_{6}\right), 29\left(\mathrm{C}_{3} \mathrm{H}_{8}\right), 32\left(\mathrm{O}_{2}\right)$ and $44\left(\mathrm{CO}_{2}\right)$. The $\mathrm{m} / \mathrm{z}$ values were selected considering the fragmentations of molecular ions of the gases so that there are no contributions in the intensities to each other. As it is demonstrated in the TPD results, the decomposition of SOMS started around $450{ }^{\circ} \mathrm{C}$ releasing short chain hydrocarbons such as methane, ethane and propane as well as hydrogen, oxygen and water. The fact that majority of the products are methane and ethane indicates the C-C bond cleavages of 
aromatic rings within the SOMS structure. The color of the material turned black after calcination, possibly indicating carbon deposition on the SOMS surface. After the reactor temperature was increased to $800^{\circ} \mathrm{C}$, the temperature was maintained for 2 hours. By then, most of the gases were liberated from the SOMS material at which the $\mathrm{m} / \mathrm{z}$ signals returned to its original intensities.

The absence of oxygen in the atmosphere led to trace amounts of $\mathrm{CO}_{2}$ formation, although slight increase in $\mathrm{CO}_{2}$ intensity was observed which can be due to remaining surface oxygen. It is important to note that the synthesis of H-SOMS is not an oxidation process; therefore, the carbon-containing organic groups are still present in the SOMS matrix.

\subsection{Surface Area, Pore Volume and Average Pore Diameter}

Table 1 shows the BET surface area, pore volume and averaged pore diameter of the samples used for this study. It was observed that the BET surface area of SOMS was increased significantly after high-temperature treatment was performed $\left(493 \mathrm{~m}^{2} / \mathrm{g} \rightarrow 682 \mathrm{~m}^{2} / \mathrm{g}\right)$. Likewise, the increase in pore volume and average pore diameter possibly indicates formation of larger pores during the calcination process. The surface area of $\mathrm{Pd} / \mathrm{H}-\mathrm{SOMS}$ is higher because $\mathrm{H}-$ SOMS was synthesized by exposing the SOMS support to a "thermal shock" treatment when acetone was fully adsorbed inside the SOMS structure. As mentioned previously, the swelling increases the internal surface area and pore volume. Therefore, when it is calcined, it retains the open-pore structure of the SOMS (H-SOMS) support obtaining higher surface area and pore volume compared to SOMS. The impregnation of Pd particles on SOMS and H-SOMS supports led to a decrease in BET surface area, pore volume and average pore diameter compared to its 
bare SOMS and H-SOMS supports, suggesting partial closure (or filling) of the pores through the impregnation process.

It should be pointed out that the $\mathrm{N}_{2}$ physisorption measurements do not show the real surface area and pore volume of swollen SOMS. The $\mathrm{N}_{2}$ adsorption on the SOMS support does not take place inside the swollen-SOMS structure; it only probes the unswollen surface of the SOMS. Due to the experimental requirements of $\mathrm{N}_{2}$ physisorption experiments such as the low-pressure and temperature during $\mathrm{N}_{2}$ adsorption and desorption, SOMS is present in the unswollen state.

\subsection{Pd Particle Size}

The Pd particle sizes of $1 \% \mathrm{Pd} / \mathrm{H}-\mathrm{SOMS}$ and $1 \% \mathrm{Pd} / \mathrm{SOMS}$ samples were measured using STEM technique (Figure 2). The particle size distribution obtained from counting 50-100 particles from the images are shown in Figure 3. With respect to Pd/SOMS, Pd particles (shown as white dots) on SOMS support are not well distributed compared to $\mathrm{Pd} / \mathrm{H}-\mathrm{SOMS}$ catalyst. The average Pd particle size for Pd/SOMS was estimated around $11 \mathrm{~nm}$ with standard deviation (SD) of $0.5 \mathrm{~nm}$. Also, larger Pd particles above $20 \mathrm{~nm}$ were observed (not shown in the figure). The non-uniform distribution of Pd particles and formation of larger Pd clusters are most likely attributed to the animated nature of the SOMS matrix during the Pd impregnation, drying and/or $\mathrm{NaBH}_{4}$ chemical reduction processes. Especially, while SOMS returns to its tensioned matrix due to evaporation of the organic solvents (acetone), it may cause relocation and agglomeration of the Pd particles.

On the other hand, the Pd particles on the H-SOMS support were smaller than on SOMS with an average Pd particle size of $3 \mathrm{~nm}$ and SD of $0.5 \mathrm{~nm}$. The Pd particles were more homogenously dispersed on H-SOMS with a narrower particle size distribution compared to $\mathrm{Pd} / \mathrm{SOMS}$ catalyst. 
As it is seen Figure 2 (a) and (b), which are on the same scale, significantly more Pd particles with a smaller particle size can be observed for Pd/H-SOMS. It is worth noting that the process of Pd impregnation on H-SOMS does not accompany with any physical expansion/compression (swelling) of the support matrix; therefore, it can be speculated that the swelling behavior plays an important role in determination of the Pd particle size.

\subsection{Chemical Structure of SOMS and H-SOMS}

\subsubsection{Infra-red spectroscopy}

IR spectra acquired over SOMS and H-SOMS were compared to understand the change in structural properties of the material due to heat treatment. Figure 4 (a) shows the spectra collected in the range of 600 to $1800 \mathrm{~cm}^{-1}$ and (b) from 1800 to $3600 \mathrm{~cm}^{-1}$. In the spectrum for SOMS, the two bands located at 1034 and $1093 \mathrm{~cm}^{-1}$ are correlated to the Si-O-Si stretching. ${ }^{55}$ The $1093 \mathrm{~cm}^{-1}$ peak is assigned to longitudinal-optic (LO)-transverse-optical (TO) splitting with an additional peak at $1188 \mathrm{~cm}^{-1},{ }^{56}$ specifically, indicating $\mathrm{LO}_{3}-\mathrm{TO}_{3}$ antisymmetric stretching, which was reported due to long range coupling of Coulomb interactions. ${ }^{57-59}$ These bands are not present in the H-SOMS spectra and are replaced with a broad $\mathrm{Si}-\mathrm{O}-\mathrm{Si}$ stretching peak characteristic of general silica materials. Volumetric expansion of H-SOMS was found to be essentially eliminated when tested using exposure to neat acetone. Therefore, the antisymmetric stretching $\mathrm{LO}_{3}(1188)-\mathrm{TO}_{3}(1093) \mathrm{cm}^{-1}$ vibration appears to be related to the swelling capability of the SOMS material.

Near the lower wavelength region of the SOMS spectrum, bands at 688 and $754 \mathrm{~cm}^{-1}$ were likely to be assigned to out-of-plane $\mathrm{C}-\mathrm{H}$ bending/wagging vibrations of mono and meta substituted benzene compounds. ${ }^{55,60}$ Similarly, for 1400 to $1700 \mathrm{~cm}^{-1}$ region, several peaks were appeared 
which were linked to in-plane C-H bending of substituted benzenes. ${ }^{60}$ These bands are not observed for H-SOMS which leads to a conclusion that almost all of the aromatic rings were decomposed due to the high temperature treatment.

The IR bands at 764,845 and $1252 \mathrm{~cm}^{-1}$ of the SOMS spectrum indicate that $\mathrm{O}-\mathrm{Si}-\left(\mathrm{CH}_{3}\right)_{3}$ are present in the SOMS material. ${ }^{55}$ The formation of trimethylsilyl group due to the derivatization of residual Si-OH during SOMS synthesis (chlorotrimethysilane treatment). ${ }^{51}$ This end-caps the residual $\mathrm{Si}-\mathrm{OH}$ groups which help to prevent additional $\mathrm{Si}-\mathrm{O}-\mathrm{Si}$ bond formation upon drying the gel, preserving flexibility of the SOMS structure. However, the intensities of the 763 and 1252 $\mathrm{cm}^{-1}$ bands significantly decrease for H-SOMS; instead, two bands of 795 and $1273 \mathrm{~cm}^{-1}$ appear in the spectrum. The shifts of 763 to $795 \mathrm{~cm}^{-1}$ and 1252 to $1273 \mathrm{~cm}^{-1}$ is relevant to generation of dimethyl groups $\left(\mathrm{O}-\mathrm{Si}-\left(\mathrm{CH}_{3}\right)_{2}-{ }^{55}{ }^{5}\right.$ This shows that the calcination of SOMS under inert conditions causes the partial destruction of the end-capped trimethylsilyl and forms additional linkages of the polysiloxane network. Si-OH bonds were not observed for neither SOMS nor HSOMS samples. Formational of additional Si-O-Si crosslinks decreases the internal flexibility and eliminates the swelling motif.

\subsection{2 ${ }^{29} \mathrm{Si} \mathrm{NMR}$}

The structure characteristics of SOMS and H-SOMS were investigated in detail using ${ }^{29} \mathrm{Si}$ NMR. Figure 5 shows the spectra collected over the Pd/SOMS and Pd/H-SOMS materials. The NMR spectrum of Pd/SOMS consists of three distinctive peaks, one at $8 \mathrm{ppm}$ and the other two at -59 ppm and $-68 \mathrm{ppm}$. The region around $8 \mathrm{ppm}$ corresponds to the $(\mathrm{SiO})-\mathrm{Si}^{*}-\mathrm{RR}^{\prime} \mathrm{R}$ ” where the center $\mathrm{Si}^{*}$ is attached to a $\mathrm{SiO}$ group and three substituents. ${ }^{61}$ In this case, all three substituents are methyl groups of $(\mathrm{SiO})-\mathrm{Si}^{*}-\left(\mathrm{CH}_{3}\right)_{3}$, showing agreement with the IR data. ${ }^{61-63}$ The peak at -59 
and $-68 \mathrm{ppm}$ are due to $(\mathrm{SiO})_{2}-\mathrm{Si}^{*}-\left(\mathrm{OCH}_{3}\right) \mathrm{R}^{63}$ and $(\mathrm{SiO})_{3}-\mathrm{Si}^{*}-\mathrm{R}^{64}$ chemical sites where $\mathrm{Si}^{*}$ is bonded to three oxygens $(\mathrm{O}) .{ }^{65}$ Specifically, it is likely that the substituted benzenes may contribute to the intensity of these two peaks. ${ }^{66}$

The spectrum for H-SOMS shows the high temperature treatment to have a significant impact on the chemical structure of SOMS. The appearance of peak around $-105 \mathrm{ppm}$ region indicates $(\mathrm{SiO})_{4}-\mathrm{Si}^{*}$ at which $\mathrm{Si}^{*}$ is linked to four $\mathrm{SiO}$ groups. ${ }^{64}$ The formation of additional $\mathrm{Si}-\mathrm{O}$ bonds is due to decomposition of SOMS releasing mostly hydrocarbons in the gas phase, but not oxygencontaining species. It can be concluded that the thermal treatment process under inert conditions transferred SOMS into a more silica-like material $\left(\mathrm{SiO}_{2}\right)$, however, it should be noted that the peak at around $-65 \mathrm{ppm}$ for $\mathrm{H}$-SOMS still indicates the presence of organic species in the $\mathrm{H}$ SOMS support matrix.

\subsection{Acetone Vapor Adsorption in Static Conditions}

The adsorption capacity and affinity of $1 \% \mathrm{Pd} / \mathrm{SOMS}$ and $1 \% \mathrm{Pd} / \mathrm{H}-\mathrm{SOMS}$ catalysts for acetone were examined in static conditions. In Figure 6, the percent increase in the mass of the two samples are plotted with respect to the exposure time to the acetone vapor. The purpose of this experiment is to confirm that the $\mathrm{Pd} / \mathrm{H}-\mathrm{SOMS}$ still has affinity towards organic molecules and preserves its hydrophobicity even though it went through a thermal shock treatment and a calcination process. Acetone vapor was used as a probe molecule since it is shown earlier that SOMS adsorbs acetone the most compared to other organic molecules including TCE. ${ }^{49}$ Pd/SOMS shows a high adsorption capacity for acetone and is highly hydrophobic (Figure 6 (a)). At 120 min of adsorption time, the mass of the Pd/SOMS increased twice to its original value. For the $\mathrm{Pd} / \mathrm{H}-\mathrm{SOMS}$ sample, the adsorption capacity for acetone was decreased compared to 
Pd/SOMS (Figure 6 (b)). As mentioned earlier, the calcination of SOMS results in reduction of swelling capability and hydrophobicity. The swelling of the SOMS structure is closely associated with the increase in pore volume and surface area, which increase the adsorption capacity of the material. Therefore, these results are expected since the extent of swelling for Pd/H-SOMS is much less than Pd/SOMS catalyst. However, as it can be seen, Pd/H-SOMS still has a higher affinity for acetone than it does for water, showing that it retains some hydrophobicity.

Figure 6 (c) compares the first five minutes of the adsorption process for both materials. The rate of adsorption of acetone is seen to be significantly faster in Pd/H-SOMS than Pd/SOMS. This result is important in showing that although the adsorption capacity of the material has decreased upon heat treatment, its rate of adsorption has increased, presumably by creating a more open pore structure.

\subsection{Accessibility of Pd to $\mathrm{CO}, \mathrm{O}_{2}$ and $\mathrm{H}_{2}$}

\subsubsection{CO chemisorption results}

$\mathrm{CO}$ chemisorption technique has been used in many studies in order to investigate the Pd dispersion on a catalyst surface. ${ }^{67-69}$ In this study, this technique was used to probe the site accessibility of the Pd particles inside the pores by introducing known volumes of $\mathrm{CO}$ to the catalyst bed using pulses. Both catalysts were pre-reduced prior $\mathrm{CO}$ chemisorption, either chemically (Pd/SOMS) or thermally using hydrogen (Pd/H-SOMS). Figure 7 shows the MS intensity for CO signal $(\mathrm{m} / \mathrm{z}=28)$ where each peak corresponds to a single pulse. As can be seen, the $\mathrm{CO}$ molecules in the first pulse were partially adsorbed by the $1 \% \mathrm{Pd} / \mathrm{H}-\mathrm{SOMS}$, specifically by the reduced Pd sites of the catalyst, whereas no adsorption of $\mathrm{CO}$ was observed for $1 \%$ $\mathrm{Pd} / \mathrm{SOMS}$. This is due to the inaccessibility of Pd sites to the incoming CO molecules in case of 
the $\mathrm{Pd} / \mathrm{SOMS}$ since in its unswollen state, the pores are closed and the $\mathrm{Pd}$ sites are sequestered inside the pores. In $\mathrm{Pd} / \mathrm{HSOMS}$, on the other hand, the pores are open and the Pd sites are accessible, leading to $\mathrm{CO}$ adsorption.

As the $\mathrm{CO}$ pulses were continued, the intensity of the $\mathrm{CO}$ peaks leveled off to the original value of the feed for Pd/H-SOMS. The \% Pd sites accessed by CO was calculated as $\sim 17 \%$ based on a ratio of $1: 1$ for $\mathrm{Pd}$ and $\mathrm{CO} .^{70-71}$

\subsubsection{In-situ XANES during oxidation, reduction and re-oxidation}

The oxidation state of Pd was followed by XANES while the catalyst was under oxidizing or reducing environments. The switches from $\mathrm{O}_{2}$ to $\mathrm{H}_{2}$ and $\mathrm{H}_{2}$ to $\mathrm{O}_{2}$ were made at 30 min and 90 min, respectively. The XANES spectra collected at $90 \mathrm{~min}$ and $150 \mathrm{~min}$ are shown in Figure 8. Spectra for references, $\mathrm{PdO}$ and metallic $\mathrm{Pd}$ are also shown in the same figure. The calculated

oxidation states are shown in Figure 9. Both samples start out with an average oxidation state of 0.94 and 0.77 for $\mathrm{Pd} / \mathrm{SOMS}$ and $\mathrm{Pd} / \mathrm{H}-\mathrm{SOMS}$, respectively. At $250{ }^{\circ} \mathrm{C}$ during the $30 \mathrm{~min}$ of oxidation, a sudden rise in Pd oxidation state in $\mathrm{Pd} / \mathrm{H}-\mathrm{SOMS}$ was observed whereas no oxidation of $\mathrm{Pd}$ was seen over the $\mathrm{Pd} / \mathrm{SOMS}$ catalyst. This can be attributed to the presence of severe mass transfer limitations for oxygen molecules to enter the catalyst pores in the SOMS support structure. In other words, it shows that most of the Pd particles are embedded inside the SOMS matrix thereby being not accessible to the incoming molecules unless they are organics. The difference is ascribed to the open-pores of the H-SOMS chemical structure where majority of the Pd particles are readily accessible.

The reduction was performed subsequently using $5 \% \mathrm{H}_{2}$ at $150{ }^{\circ} \mathrm{C}$. After $15 \mathrm{~min}$ of reduction, all the samples were significantly reduced reaching an oxidation state of 0.20 and 0.15 for 
$\mathrm{Pd} / \mathrm{SOMS}$ and $\mathrm{Pd} / \mathrm{H}-\mathrm{SOMS}$, respectively. Likewise, at $250{ }^{\circ} \mathrm{C}$, the extent of reduction of $\mathrm{Pd} / \mathrm{H}-$ SOMS and Pd/SOMS were maintained close to $\mathrm{Pd}^{0}$. The reduction of $\mathrm{Pd}$ of $\mathrm{Pd} / \mathrm{SOMS}$ catalyst is interesting, especially considering the fact that oxygen was not able to access the Pd sites. Therefore, it is probable that the adsorption takes place depending on the size of the molecule, i.e. hydrogen molecule is much smaller than oxygen. The SOMS support acts as a molecular sieve where larger molecules are not allowed to pass through to get in contact with the Pd particles located inside the SOMS matrix. However, it should be pointed out that this is only valid when $\mathrm{Pd} / \mathrm{SOMS}$ is in unswollen state. Regardless of the molecular size, Pd sites are accessible to the reactants if the SOMS is in the swollen state.

Re-oxidation of the samples was carried out following the reduction treatment. Again, similar to the conclusion made previously, Pd supported on SOMS remained in a more reduced state compared Pd supported on H-SOMS.

\subsection{Gas-Phase HDC of TCE}

\subsubsection{Catalytic Activity}

The catalytic performances of $1 \% \mathrm{Pd} / \mathrm{SOMS}$ and $1 \% \mathrm{Pd} / \mathrm{H}-\mathrm{SOMS}$ were investigated for gasphase HDC of TCE. The reaction was performed in a continuous gas-phase fixed bed reactor system at reaction temperatures of 100,150 and $200{ }^{\circ} \mathrm{C}$. It is expected that there will be an influence of the reaction temperatures on the textural and morphological characteristics of Pd/SOMS. Pd/HSOMS, on the other hand, is thermally more stable and less sensitive since the support SOMS was treated at $600{ }^{\circ} \mathrm{C}$ before Pd impregnation. Although no characterization was 
performed on the post-reaction catalysts, effect of the reaction conditions on the material characteristics of Pd/HSOMS are expected to be smaller than that on Pd/SOMS.

The TCE conversions obtained over the two samples are shown in Table 2. As expected, $1 \%$ Pd/SOMS was significantly less active for gas-phase HDC of TCE reaction in the entire temperature range compared to the $1 \% \mathrm{Pd} / \mathrm{H}-\mathrm{SOMS}$ catalyst. This is attributed to the lower degree of swelling of the Pd/SOMS sample in the gas-phase compared to liquid-phase, which results in a decrease in the number of Pd active sites available for the HDC of TCE. It should be noted that the actual number of accessible metallic Pd sites over Pd/SOMS during the HDC reaction is certainly higher since, during the approach to steady-state, SOMS support swells, opening the pores, as seen in our previous work. ${ }^{49}$ The adsorption of TCE increases the availability of the Pd metal in the SOMS matrix by opening up the catalyst pores while physical expansion of the Pd/SOMS catalyst proceeds. However, for gas-phase HDC of TCE, a significantly low catalytic performance of $1 \% \mathrm{Pd} / \mathrm{SOMS}$ was obtained. Thus, whether the pores are opened enough so that Pd active sites are all accessible for the HDC reaction in the gas-phase remains as a question. In addition, the fact that an opposite trend was obtained in liquid-phase HDC of TCE where the $1 \% \mathrm{Pd} / \mathrm{SOMS}$ catalyst was more active than $1 \% \mathrm{Pd} / \mathrm{Al}_{2} \mathrm{O}_{3}$ (data not shown) supports the statement that the swelling, i.e. expansion of the volume of SOMS, is somewhat limited in the gas phase.

When Pd was impregnated on calcined SOMS under inert conditions (Pd/H-SOMS), a significant improvement of the catalytic activity was observed. This is in good agreement with the $\mathrm{CO}$ chemisorption results where more Pd metallic sites were shown to be accessible. Thus, an increased conversion level from $\mathrm{Pd} / \mathrm{H}-\mathrm{SOMS}$ is expected, since under gas-phase conditions at 
elevated temperature the amount of adsorption of TCE is insufficient to open the pores of $\mathrm{Pd} / \mathrm{SOMS}$ to allow access to "sequestered" catalytic sites. At $200{ }^{\circ} \mathrm{C}$, the TCE conversion obtained over the $\mathrm{Pd} / \mathrm{H}-\mathrm{SOMS}$ catalyst was $92.5 \%$ whereas only $38.3 \%$ was obtained over Pd/SOMS.

The main products of HDC of TCE is hydrogen chloride $(\mathrm{HCl})$ and ethane $\left(\mathrm{C}_{2} \mathrm{H}_{6}\right)$. As shown in the Table 2, Pd/H-SOMS showed a higher HDC percentage and higher ethane selectivity. Among the by-products, partially dechlorinated products such as cis-1,2 DCE and 1,1 DCE gave higher yields compared to trans-1,2 DCE, especially when lower TCE conversions were obtained. Ethylene was acquired in large amounts over the Pd/SOMS at higher temperatures. Also, vinyl

chloride and even number of higher-carbon products such as $n$-butane were observed. ${ }^{23,} 72$ Significant catalyst coking was observed at a reaction temperature of $200{ }^{\circ} \mathrm{C}$ for $\mathrm{Pd} / \mathrm{H}-\mathrm{SOMS}$ catalysts, indicating that $\mathrm{Pd}$ sites have both $\mathrm{C}-\mathrm{Cl}$ and $\mathrm{C}-\mathrm{C}$ bond cleavage activity.

\subsubsection{Effect of Addition of Water}

The effect of the addition of water vapor to the reactant stream on catalytic activities of $1 \%$ $\mathrm{Pd} / \mathrm{SOMS}$ and $1 \% \mathrm{Pd} / \mathrm{H}-\mathrm{SOMS}$ was also examined (Table 3). The addition of water to the reactant mixture did not affect the catalytic performance of the $\mathrm{Pd} / \mathrm{H}-\mathrm{SOMS}$ or $\mathrm{Pd} / \mathrm{SOMS}$ catalysts. The TCE conversion levels in the absence and presence of water were very similar (Figure 10). This is mainly attributed to the strong hydrophobicity of SOMS and H-SOMS supports that repels the water molecules thereby restricting the adsorption of water on the catalyst surface. Even though, the degree of hydrophobicity of the H-SOMS was somewhat reduced compared to SOMS, the results show that the inhibition effect of water on the catalytic 
activity of $\mathrm{Pd} / \mathrm{H}-\mathrm{SOMS}$ is negligible. However, at $200{ }^{\circ} \mathrm{C}$, as observed before, carbon deposition on the $\mathrm{Pd} / \mathrm{H}-\mathrm{SOMS}$ catalyst was encountered.

\section{Conclusions}

The catalytic performance of Pd supported on SOMS and high-temperature treated SOMS (HSOMS) was investigated for the gas-phase HDC of TCE. In our previous results, it was reported that $1 \% \mathrm{Pd} / \mathrm{SOMS}$ has shown significantly better catalytic performance compared to $1 \%$ $\mathrm{Pd} / \mathrm{Al}_{2} \mathrm{O}_{3}$ catalyst under liquid-phase $\mathrm{HDC}$ of TCE conditions. This was attributed to the swelling capability of SOMS which concentrated the TCE reactants in the vicinity of the Pd active sites. However, in the gas-phase, the catalyst pores of Pd/SOMS were not fully open, thereby leading to lower catalytic of $\mathrm{Pd} / \mathrm{SOMS}$ than $\mathrm{Pd} / \mathrm{Al}_{2} \mathrm{O}_{3}$. Thus, in this study, a sample of SOMS saturated with acetone was calcined under inert conditions at high temperature in order to retain its swollen state resulting better pore accessibility. The surface analysis results exhibited higher BET surface area, pore volume and averaged pore diameter over the H-SOMS material compared to SOMS. After Pd was placed on both supports, the Pd dispersion of Pd/H-SOMS was greatly improved than that of Pd/SOMS based on the STEM images. Also, the average Pd particle size was smaller for Pd/H-SOMS. XANES results exhibited that Pd sites on H-SOMS were accessible to both $\mathrm{H}_{2}$ and $\mathrm{O}_{2}$ allowing reduction and oxidation of the Pd sites readily. However, in the case of Pd/SOMS, the accessibility of Pd sites was significantly limited for $\mathrm{O}_{2}$ species thereby showing lesser oxidation of Pd particles under the same reaction conditions

compared to Pd/H-SOMS. For gas-phase HDC of TCE, higher TCE conversions were achieved over the $\mathrm{Pd} / \mathrm{H}-\mathrm{SOMS}$ catalyst compared to $\mathrm{Pd} / \mathrm{SOMS}$. In the presence of water, both $\mathrm{Pd} / \mathrm{SOMS}$ 
and $\mathrm{Pd} / \mathrm{H}-\mathrm{SOMS}$ catalysts retained their catalytic activities, which was attributed to the hydrophobicity of the supports.

\section{Acknowledgements}

The financial support for this work was provided by the National Science Foundation through the

Grant CBET-1436729. The authors also acknowledge partial support provided by the Ohio Coal Research Consortium.

MRCAT operations are supported by the Department of Energy and the MRCAT member institutions. This research used resources of the Advanced Photon Source, a U.S. Department of Energy (DOE) Office of Science User Facility operated for the DOE Office of Science by Argonne National Laboratory under Contract No. DE-AC02-06CH11357 


\section{References}

1. Bakke, B.; Stewart, P. A.; Waters, M. A., Uses of and Exposure to Trichloroethylene in U.S. Industry: A Systematic Literature Review. Journal of Occupational and Environmental Hygiene 2007, 4, 375-390.

2. Doherty, R. E., A History of the Production and Use of Carbon Tetrachloride, Tetrachloroethylene, Trichloroethylene and 1,1,1-Trichloroethane in the United States: Part 1-Historical Background; Carbon Tetrachloride and Tetrachloroethylene. Environmental Forensics 2000, 1, 69-81.

3. U.S, E. P. A., Toxicological Review of Trichloroethylene "in Support of Summary Information on the Integrated Risk Information System (Iris)". U.S. Environmental Protection Agency: Washington, DC, 2011.

4. Hansen, J., et al., Risk of Cancer among Workers Exposed to Trichloroethylene: Analysis of Three Nordic Cohort Studies. Journal Of The National Cancer Institute 2013, 105, 869-877.

5. Moran, M. J.; Zogorski, J. S.; Squillace, P. J., Chlorinated Solvents in Groundwater of the United States. Environmental Science \& Technology 2006, 41, 74-81.

6. U.S, E. P. A. Occurrence Estimation Methodology and Occurrence Findings Report of the Six-Year Review of Existing National Primary Drinking Water Regulations; EPA-815/R-03-006; Washington, DC, 2003.

7. (ATSDR), A. f. T. S. a. D. R., Toxicological Profile for Trichloroethylene (Tce) (Draft for Public Comment). U.S. Department of Health and Human Services, P. H. S., Ed. Atlanta, GA, 2014.

8. Miyake, Y.; Sakoda, A.; Yamanashi, H.; Kaneda, H.; Suzuki, M., Activated Carbon Adsorption of Trichloroethylene (Tce) Vapor Stripped from Tce-Contaminated Water. Water Research 2003, 37, 18521858.

9. Blanford, W. J.; Klingel, E. J.; Johnson, G. R.; Cain, R. B.; Enfield, C.; Brusseau, M. L., Performance Assessment of in-Well Aeration for the Remediation of an Aquifer Contaminated by a Multicomponent Immiscible Liquid. 1999, 725, 167-181.

10. Kim, H.; Ahn, D.; Annable, M. D., Enhanced Removal of Vocs from Aquifers During Air Sparging Using Thickeners and Surfactants: Bench-Scale Experiments. J Contam Hydrol 2016, 184, 25-34.

11. Russell, H. H.; Matthews, J. E.; Sewell, G. W. Tce Removal from Contaminated Soil and Ground Water. Ground Water Issue; Environ. Protect. Agency: 1992; p 12 pp.

12. Van der Avert, P.; Weckhuysen, B. M., Low-Temperature Destruction of Chlorinated Hydrocarbons over Lanthanide Oxide Based Catalysts. Angewandte Chemie International Edition 2002, 41, 4730-4732.

13. Nakano, Y.; Hua, L. Q.; Nishijima, W.; Shoto, E.; Okada, M., Biodegradation of Trichloroethylene (Tce) Adsorbed on Granular Activated Carbon (Gac). Water research 2000, 34, 4139-4142.

14. Zouboulis, A. I.; Moussas, P. A., Groundwater and Soil Pollution: Bioremediation. In Encyclopedia of Environmental Health, Nriagu, J. O., Ed. Elsevier: Burlington, 2011; pp 1037-1044.

15. Liang, C.; Bruell, C. J.; Marley, M. C.; Sperry, K. L., Persulfate Oxidation for in Situ Remediation of Tce. I. Activated by Ferrous Ion with and without a Persulfate-Thiosulfate Redox Couple. Chemosphere 2004, 55, 1213-23.

16. Li, X. D.; Schwartz, F. W., Dnapl Remediation with in Situ Chemical Oxidation Using Potassium Permanganate. Journal of Contaminant Hydrology 2004, 68, 39-53. 
17. Ordóñez, S.; Sastre, H.; Díez, F. V., Hydrodechlorination of Aliphatic Organochlorinated Compounds over Commercial Hydrogenation Catalysts. Applied Catalysis B: Environmental 2000, 25, 4958.

18. Cobo, M.; Becerra, J.; Castelblanco, M.; Cifuentes, B.; Conesa, J. A., Catalytic Hydrodechlorination of Trichloroethylene in a Novel Naoh/2-Propanol/Methanol/Water System on Ceria-Supported Pd and Rh Catalysts. J Environ Manage 2015, 158, 1-10.

19. Barrabés, N.; Föttinger, K.; Llorca, J.; Dafinov, A.; Medina, F.; Sá, J.; Hardacre, C.; Rupprechter, G. n., Pretreatment Effect on Pt/Ceo2 Catalyst in the Selective Hydrodechlorination of Trichloroethylene. The Journal of Physical Chemistry C 2010, 114, 17675-17682.

20. Lowry, G. V.; Reinhard, M., Pd-Catalyzed Tce Dechlorination in Water: Effect of [H2](Aq) H2Utilizing Competitive Solutes on the Tce Dechlorination Rate and Product Distribution. Environmental Science \&amp; Technology 2001, 35, 696-702.

21. Davie, M. G.; Cheng, H.; Hopkins, G. D.; LeBron, C. A.; Reinhard, M., Implementing Heterogeneous Catalytic Dechlorination Technology for Remediating Tce-Contaminated Groundwater. Environmental science \& technology 2008, 42, 8908-8915.

22. Liu; He, F.; Durham, E.; Zhao, D.; Roberts, C. B., Polysugar-Stabilized Pd Nanoparticles Exhibiting High Catalytic Activities for Hydrodechlorination of Environmentally Deleterious Trichloroethylene. Langmuir 2007, 24, 328-336.

23. Sriwatanapongse, W.; Reinhard, M.; Klug, C. A., Reductive Hydrodechlorination of Trichloroethylene by Palladium-on-Alumina Catalyst: 13c Solid-State Nmr Study of Surface Reaction Precursors. Langmuir 2006, 22, 4158-4164.

24. Nutt, M. O.; Heck, K. N.; Alvarez, P.; Wong, M. S., Improved Pd-on-Au Bimetallic Nanoparticle Catalysts for Aqueous-Phase Trichloroethene Hydrodechlorination. Applied Catalysis B: Environmental 2006, 69, 115-125.

25. Díaz, E.; McCall, A.; Faba, L.; Sastre, H.; Ordóñez, S., Trichloroethylene Hydrodechlorination in Water Using Formic Acid as Hydrogen Source: Selection of Catalyst and Operation Conditions. Environmental Progress \& Sustainable Energy 2013, 32, 1217-1222.

26. Munakata, N.; Reinhard, M., Palladium Catalysis for the Treatment of Contaminated Waters: A Review. In Physicochemical Groundwater Remediation, Springer: 2002; pp 45-71.

27. Ordonez, S.; Vivas, B. P.; Diez, F. V., Minimization of the Deactivation of Palladium Catalysts in the Hydrodechlorination of Trichloroethylene in Wastewaters. Applied Catalysis B, Environmental 2010, 95, 288-296.

28. Yu, X.; Wu, T.; Yang, X. J.; Xu, J.; Auzam, J.; Semiat, R.; Han, Y. F., Degradation of Trichloroethylene by Hydrodechlorination Using Formic Acid as Hydrogen Source over Supported Pd Catalysts. J Hazard Mater 2016, 305, 178-89.

29. Śrębowata, A.; Tarach, K.; Girman, V.; Góra-Marek, K., Catalytic Removal of Trichloroethylene from Water over Palladium Loaded Microporous and Hierarchical Zeolites. Applied Catalysis B: Environmental 2016, 181, 550-560.

30. Lowry, G. V.; Reinhard, M., Hydrodehalogenation of 1-to 3-Carbon Halogenated Organic Compounds in Water Using a Palladium Catalyst and Hydrogen Gas. Environmental science \& technology 1999, 33, 1905-1910.

31. Nutt, M. O.; Hughes, J. B.; Wong, M. S., Designing Pd-on-Au Bimetallic Nanoparticle Catalysts for Trichloroethene Hydrodechlorination. Environmental Science \& Technology 2005, 39, 1346-1353.

32. Zhang, M.; Bacik, D. B.; Roberts, C. B.; Zhao, D., Catalytic Hydrodechlorination of Trichloroethylene in Water with Supported Cmc-Stabilized Palladium Nanoparticles. Water Research 2013, 47, 3706-3715. 
33. He, F.; Liu, J.; Roberts, C. B.; Zhao, D., One-Step "Green" Synthesis of Pd Nanoparticles of Controlled Size and Their Catalytic Activity for Trichloroethene Hydrodechlorination. Industrial \& Engineering Chemistry Research 2009, 48, 6550-6557.

34. Navon, R.; Eldad, S.; Mackenzie, K.; Kopinke, F.-D., Protection of Palladium Catalysts for Hydrodechlorination of Chlorinated Organic Compounds in Wastewaters. Applied Catalysis B: Environmental 2012, 119-120, 241-247.

35. Kopinke, F.-D.; Angeles-Wedler, D.; Fritsch, D.; Mackenzie, K., Pd-Catalyzed Hydrodechlorination of Chlorinated Aromatics in Contaminated Waters-Effects of Surfactants, Organic Matter and Catalyst Protection by Silicone Coating. Applied Catalysis B: Environmental 2010, 96, 323-328.

36. Comandella, D.; Woszidlo, S.; Georgi, A.; Kopinke, F.-D.; Mackenzie, K., Efforts for Long-Term Protection of Palladium Hydrodechlorination Catalysts. Applied Catalysis B: Environmental 2016, 186, 204-211.

37. Wei, J.; Qian, Y.; Wang, L.; Ge, Y.; Su, L.; Zhai, D.; Wang, J.; Wang, J.; Yu, J., Enhancement of Degradation and Dechlorination of Trichloroethylene Via Supporting Palladium/Iron Bimetallic Nanoparticles onto Mesoporous Silica. Catalysts 2016, 6, 105.

38. Han, Y.; Liu, C.; Horita, J.; Yan, W., Trichloroethene Hydrodechlorination by Pd-Fe Bimetallic Nanoparticles: Solute-Induced Catalyst Deactivation Analyzed by Carbon Isotope Fractionation. Applied Catalysis B: Environmental 2016, 188, 77-86.

39. Li, X.-q.; Elliott, D. W.; Zhang, W.-X., Zero-Valent Iron Nanoparticles for Abatement of Environmental Pollutants: Materials and Engineering Aspects. Critical Reviews in Solid State and Materials Sciences 2006, 31, 111-122.

40. Lien, H.-L.; Zhang, W.-X., Nanoscale Pd/Fe Bimetallic Particles: Catalytic Effects of Palladium on Hydrodechlorination. Applied Catalysis B: Environmental 2007, 77, 110-116.

41. Wu, L.; Ritchie, S. M., Removal of Trichloroethylene from Water by Cellulose Acetate Supported Bimetallic Ni/Fe Nanoparticles. Chemosphere 2006, 63, 285-92.

42. Lin, C. J.; Lo, S. L.; Liou, Y. H., Dechlorination of Trichloroethylene in Aqueous Solution by Noble Metal-Modified Iron. Journal of Hazardous Materials 2004, 116, 219-228.

43. Tee, Y.-H.; Grulke, E.; Bhattacharyya, D., Role of Ni/Fe Nanoparticle Composition on the Degradation of Trichloroethylene from Water. Industrial \& Engineering Chemistry Research 2005, 44, 7062-7070.

44. Guo, Q.; Ren, L., Hydrodechlorination of Trichloroethylene over Mop/Г-Al2o3 Catalyst with High Surface Area. Catalysis Today 2016, 264, 158-162.

45. Liu, X.; Ren, L., The Influence of Polyethylene Glycol on the Synthesis and Activity of Mop for the Hydrodechlorination of Trichloroethylene. RSC Adv. 2016, 6, 7413-7418.

46. Finocchio, E.; Sapienza, G.; Baldi, M.; Busca, G., Trichloroethylene Catalytic Conversion over Acidic Solid Catalysts. Applied Catalysis B: Environmental 2004, 51, 143-148.

47. Meshesha, B. T.; Barrabés, N.; Llorca, J.; Dafinov, A.; Medina, F.; Föttinger, K., Pdcu Alloy Nanoparticles on Alumina as Selective Catalysts for Trichloroethylene Hydrodechlorination to Ethylene. Applied Catalysis A: General 2013, 453, 130-141.

48. Meshesha, B. T.; Barrabés, N.; Föttinger, K.; Chimentão, R. J.; Llorca, J.; Medina, F.; Rupprechter, G.; Sueiras, J. E., Gas-Phase Hydrodechlorination of Trichloroethylene over Pd/Nimgal Mixed Oxide Catalysts. Applied Catalysis B: Environmental 2012, 117-118, 236-245.

49. Sohn, H.; Celik, G.; Gunduz, S.; Dean, S. L.; Painting, E.; Edmiston, P. L.; Ozkan, U. S., Hydrodechlorination of Trichloroethylene over Pd Supported on Swellable Organically-Modified Silica (Soms). Applied Catalysis B: Environmental 2017, 203, 641-653.

50. Edmiston, P. L.; Underwood, L. A., Absorption of Dissolved Organic Species from Water Using Organically Modified Silica That Swells. Separation and Purification Technology 2009, 66, 532-540. 
51. Burkett, C. M.; Edmiston, P. L., Highly Swellable Sol-Gels Prepared by Chemical Modification of Silanol Groups Prior to Drying. Journal of non-Crystalline Solids 2005, 351, 3174-3178.

52. Burkett, C. M.; Underwood, L. A.; Volzer, R. S.; Baughman, J. A.; Edmiston, P. L., OrganicInorganic Hybrid Materials That Rapidly Swell in Non-Polar Liquids: Nanoscale Morphology and Swelling Mechanism. Chemistry of Materials 2008, 20, 1312-1321.

53. Edmiston, P. L. Swellable Sol-Gels, Methods of Making, and Use Thereof. US8119759 B2, 2012.

54. Edmiston, P. L. Swellable Materials and Methods of Use US 8,367,793 B2, 2013.

55. Launer, P. J., Infrared Analysis of Organosilicon Compounds: Spectra-Structure Correlations. Silicone compounds register and review 1987, 100.

56. Almeida, R. M.; Pantano, C. G., Structural Investigation of Silica Gel Films by Infrared Spectroscopy. Journal of Applied Physics 1990, 68, 4225-4232.

57. Galeener, F.; Lucovsky, G., Longitudinal Optical Vibrations in Glasses: $\mathrm{GeO}_{2}$ and $\mathrm{SiO}_{2}$. Physical Review Letters 1976, 37, 1474-1478.

58. Payne, M.; Inkson, J., Longitudinal-Optic-Transverse-Optic Vibrational Mode Splittings in Tetrahedral Network Glasses. Journal of non-Crystalline solids 1984, 68, 351-360.

59. De Leeuw, S.; Thorpe, M. F., Coulomb Splittings in Glasses. Physical Review letters 1985, 55, 2879.

60. Lin-Vien, D.; Colthup, N. B.; Fateley, W. G.; Grasselli, J. G., The Handbook of Infrared and Raman Characteristic Frequencies of Organic Molecules; Elsevier, 1991.

61. lacopi, F.; Beyer, G.; Travaly, Y.; Waldfried, C.; Gage, D. M.; Dauskardt, R. H.; Houthoofd, K.; Jacobs, P.; Adriaensens, P.; Schulze, K., Thermomechanical Properties of Thin Organosilicate Glass Films Treated with Ultraviolet-Assisted Cure. Acta Materialia 2007, 55, 1407-1414.

62. Rulkens, R.; Ni, Y.; Manners, I., Living Anionic Ring-Opening Polymerization of Silicon-Bridged [1] Ferrocenophanes: Synthesis and Characterization of Poly (Ferrocenylsilane)-Polysiloxane Block Copolymers. Journal of the American Chemical Society 1994, 116, 12121-12122.

63. Mabboux, P.-Y.; Gleason, K. K., Chemical Bonding Structure of Low Dielectric Constant Si:O:C:H Films Characterized by Solid-State Nmr. Journal of The Electrochemical Society 2005, 152, F7-F13.

64. Yang, J. J.; El-Nahhal, I. M.; Chuang, I.-S.; Maciel, G. E., Synthesis and Solid-State Nmr Structural Characterization of Polysiloxane-Immobilized Amine Ligands and Their Metal Complexes. Journal of nonCrystalline solids 1997, 209, 19-39.

65. Shimojima, A.; Mochizuki, D.; Kuroda, K., Synthesis of Silylated Derivatives of a Layered Polysilicate Kanemite with Mono-, Di-, and Trichloro (Alkyl) Silanes. Chemistry of Materials 2001, 13, 3603-3609.

66. Choi, S.; Kim, Y.; Kim, I.; Ha, C.-S., Effect of Organosilica Isomers on the Interfacial Interaction in Polyimide/Aromatic Organosilica Hybrids. Journal of Applied Polymer Science 2007, 103, 2507-2513.

67. Kast, P.; Friedrich, M.; Teschner, D.; Girgsdies, F.; Lunkenbein, T.; Naumann d'Alnoncourt, R.; Behrens, M.; Schlögl, R., Co Oxidation as a Test Reaction for Strong Metal-Support Interaction in Nanostructured Pd/Feox Powder Catalysts. Applied Catalysis A: General 2015, 502, 8-17.

68. Mahata, N.; Vishwanathan, V., Influence of Palladium Precursors on Structural Properties and Phenol Hydrogenation Characteristics of Supported Palladium Catalysts. Journal of Catalysis 2000, 196, 262-270.

69. Somboonthanakij, S.; Mekasuwandumrong, O.; Panpranot, J.; Nimmanwudtipong, T.; Strobel, R.; Pratsinis, S. E.; Praserthdam, P., Characteristics and Catalytic Properties of Pd/Sio2 Synthesized by OneStep Flame Spray Pyrolysis in Liquid-Phase Hydrogenation of 1-Heptyne. Catalysis Letters 2007, 119, 346-352. 
70. Verho, O.; Zheng, H.; Gustafson, K. P. J.; Nagendiran, A.; Zou, X.; Bäckvall, J.-E., Application of Pd Nanoparticles Supported on Mesoporous Hollow Silica Nanospheres for the Efficient and Selective Semihydrogenation of Alkynes. Chem CatChem 2016, 8, 773-778.

71. Wu, K.; Qian, X.; Chen, L.; Xu, Z.; Zheng, S.; Zhu, D., Effective Liquid Phase Hydrodechlorination of Diclofenac Catalysed by Pd/Ceo2. RSC Adv. 2015, 5, 18702-18709.

72. Schrick, B.; Blough, J. L.; Jones, A. D.; Mallouk, T. E., Hydrodechlorination of Trichloroethylene to Hydrocarbons Using Bimetallic Nickel-Iron Nanoparticles. Chemistry of Materials 2002, 14, 5140-5147. 
Table 1. BET Surface area, pore volume and average pore diameter of SOMS, H-SOMS, $1 \%$ $\mathrm{Pd} / \mathrm{SOMS}$ and $1 \% \mathrm{Pd} / \mathrm{H}-\mathrm{SOMS}$

\begin{tabular}{|cccc|}
\hline & BET Surface Area & Pore Volume & Averaged Pore Diameter \\
\hline & $\left(\mathrm{m}^{2} / \mathrm{g}\right)$ & $\left(\mathrm{cm}^{3} / \mathrm{g}\right)$ & $(\AA)$ \\
\hline H-SOMS & 493 & 1.03 & 84 \\
\hline $1 \% \mathrm{Pd} / \mathrm{SOMS}$ & 682 & 2.07 & 122 \\
$1 \% \mathrm{Pd} / \mathrm{H}-\mathrm{SOMS}$ & 479 & 0.56 & 47 \\
\hline
\end{tabular}


Table 2. Gas-phase catalytic activity data of Pd/SOMS and Pd/H-SOMS for HDC of TCE

\begin{tabular}{|c|c|c|c|c|c|c|}
\hline & \multicolumn{3}{|c|}{ Pd/SOMS } & \multicolumn{3}{|c|}{ Pd/H-SOMS } \\
\hline & $100^{\circ} \mathrm{C}$ & $150^{\circ} \mathrm{C}$ & $200^{\circ} \mathrm{C}$ & $100^{\circ} \mathrm{C}$ & $150^{\circ} \mathrm{C}$ & $200{ }^{\circ} \mathrm{C}$ \\
\hline$\% \mathrm{HDC}$ & 4.2 & 7.7 & 25.6 & 5.2 & 24 & 87.8 \\
\hline \% TCE Conv. & 9.3 & 13.7 & 38.3 & 10.2 & 34.8 & 92.5 \\
\hline \multicolumn{7}{|l|}{ Selectivity (\%) } \\
\hline Ethane & 9.0 & 12.3 & 18.6 & 19.6 & 44.2 & 71.4 \\
\hline Ethylene & 4.3 & 15.2 & 29 & 3.9 & 6.9 & 15.5 \\
\hline Vinyl Chloride & 5.3 & 10.9 & 5.0 & 3.9 & 2.2 & 0.6 \\
\hline n-butane & 4.3 & 0.7 & 1.0 & 4.9 & 4.9 & 3.1 \\
\hline 1,1 DCE & 31.0 & 26.8 & 19.3 & 18.7 & 15.5 & 4.3 \\
\hline trans-1,2 DCE & 3.3 & 1.6 & 1.2 & 9.8 & 4.0 & 2.1 \\
\hline cis-1,2 DCE & 42.8 & 32.6 & 25.9 & 39.2 & 22.3 & 2.9 \\
\hline
\end{tabular}


Table 3. Effect of addition of water in the reactant stream on catalytic activity of Pd/SOMS and $\mathrm{Pd} / \mathrm{H}-\mathrm{SOMS}$

\begin{tabular}{|c|c|c|c|c|c|c|}
\hline & \multicolumn{3}{|c|}{ Pd/SOMS } & \multicolumn{3}{|c|}{ Pd/H-SOMS } \\
\hline & $100^{\circ} \mathrm{C}$ & $150^{\circ} \mathrm{C}$ & $200^{\circ} \mathrm{C}$ & $100^{\circ} \mathrm{C}$ & $150^{\circ} \mathrm{C}$ & $200{ }^{\circ} \mathrm{C}$ \\
\hline$\% \mathrm{HDC}$ & 5.0 & 9.1 & 22.8 & 5.6 & 29.3 & 92.1 \\
\hline \% TCE Conv. & 10.1 & 16.6 & 35.3 & 11.1 & 40.9 & 96.6 \\
\hline \multicolumn{7}{|l|}{ Selectivity (\%) } \\
\hline Ethane & 11.9 & 12 & 15.9 & 23.4 & 48.4 & 85.6 \\
\hline Ethylene & 6.9 & 14.5 & 25.8 & 0.9 & 5.9 & 3.3 \\
\hline Vinyl Chloride & 6.9 & 9.0 & 4.2 & 1.8 & 2.7 & 0.3 \\
\hline n-butane & 5.0 & 6.0 & 11.6 & 3.6 & 6.6 & 5.9 \\
\hline $1,1 \mathrm{DCE}$ & 21.8 & 22.3 & 17.6 & 21.6 & 13.2 & 1.4 \\
\hline trans-1,2 DCE & 7.9 & 7.2 & 0.8 & 5.4 & 3.9 & 2.1 \\
\hline cis-1,2 DCE & 39.6 & 28.9 & 24.1 & 43.2 & 19.3 & 1.4 \\
\hline
\end{tabular}




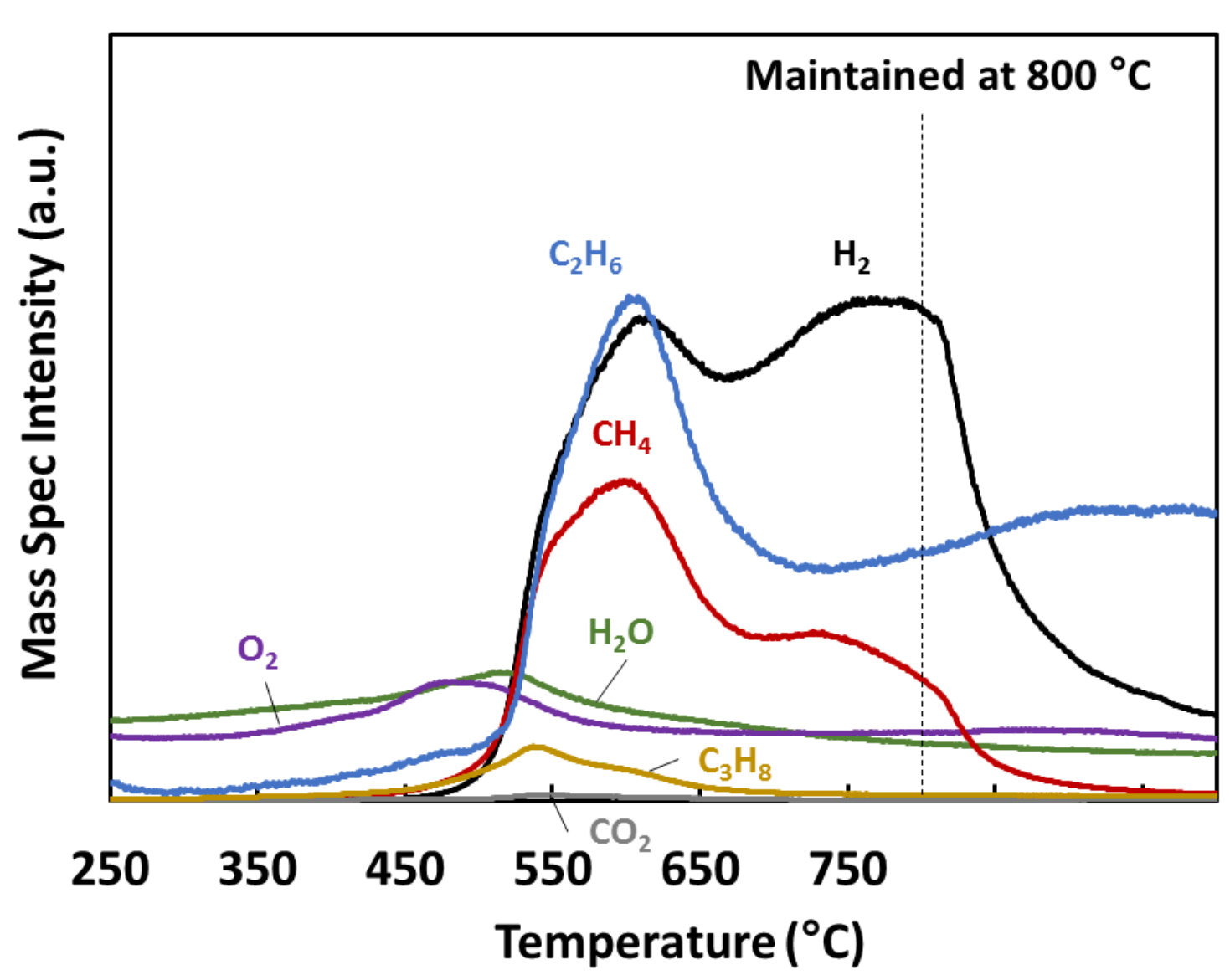

Figure 1. Evolved species during temperature programmed decomposition of SOMS under helium 


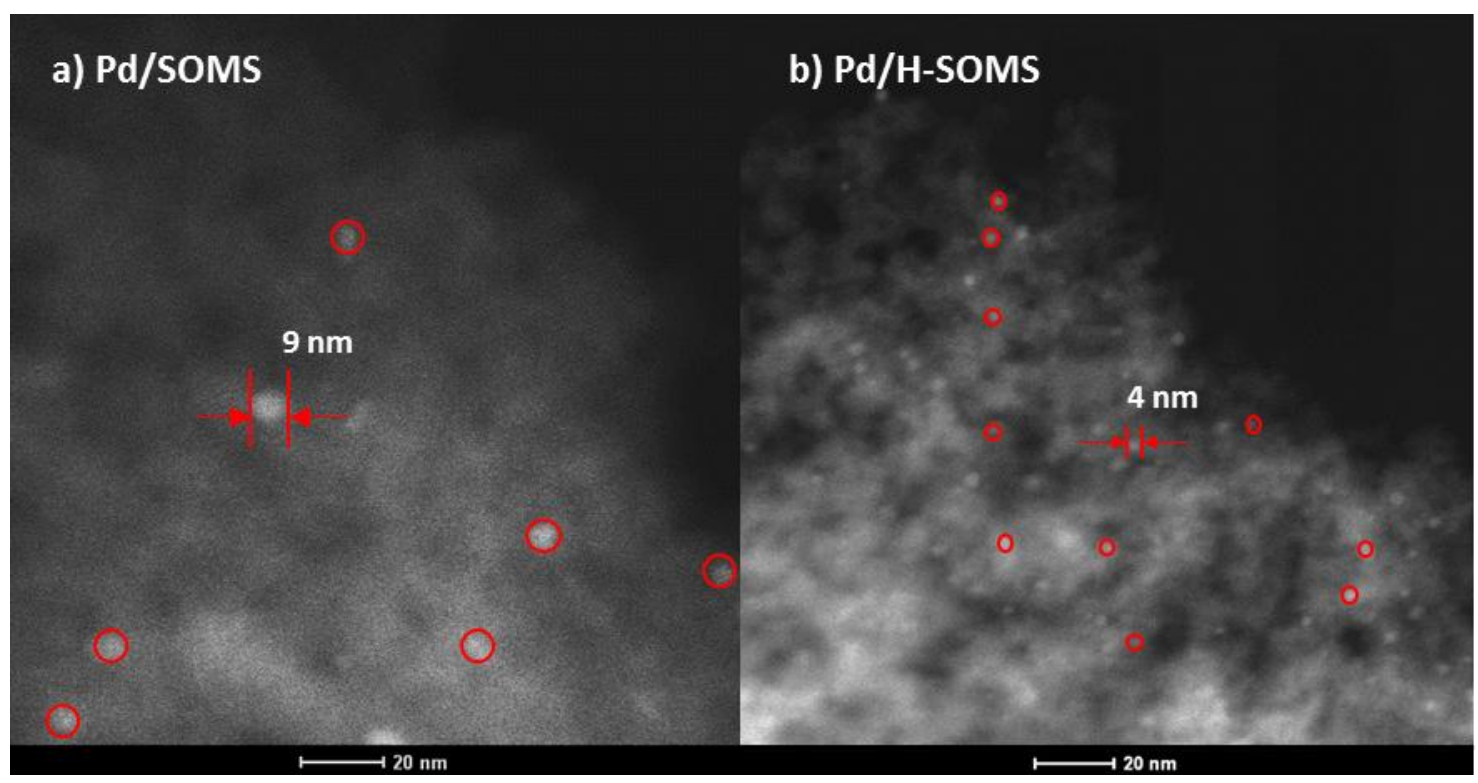

Figure 2. STEM images of $\mathrm{Pd} / \mathrm{SOMS}$ and $\mathrm{Pd} / \mathrm{H}-\mathrm{SOMS}$ (white dots represents $\mathrm{Pd}$ particles) 


\section{(a) Pd/SOMS}

Average: $11 \mathrm{~nm}$ SD: $6 \mathrm{~nm}$

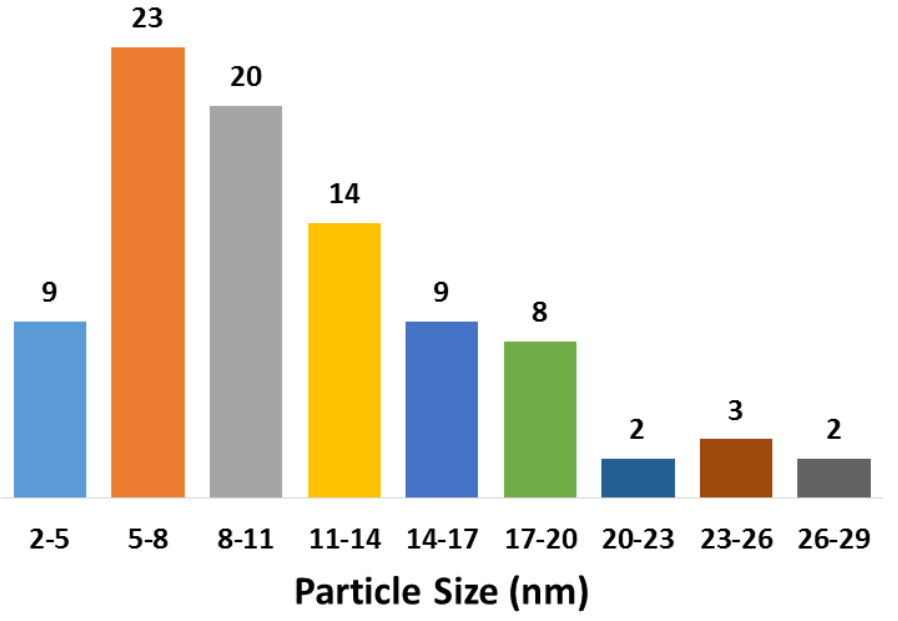

(b) Pd/H-SOMS

15

Average: $2.8 \mathrm{~nm}$ SD: $0.5 \mathrm{~nm}$
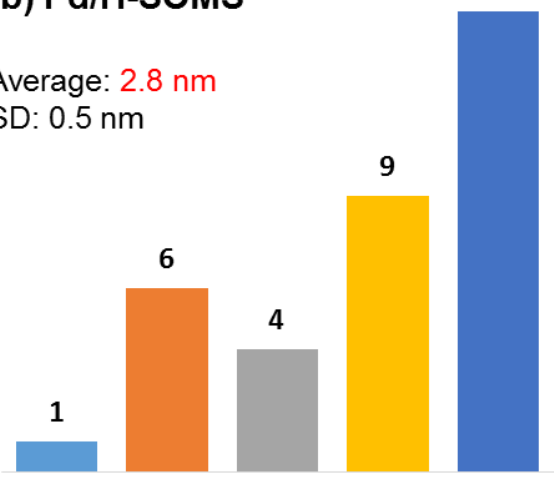

9

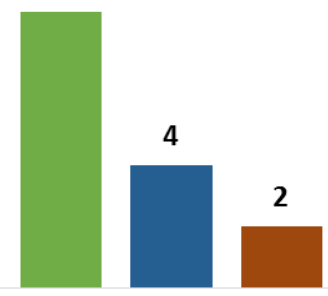

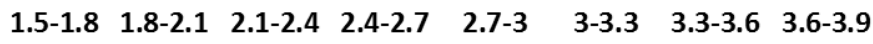

Particle Size $(\mathrm{nm})$

Figure 3. Particle Size Distribution for Pd/SOMS and Pd/H-SOMS 

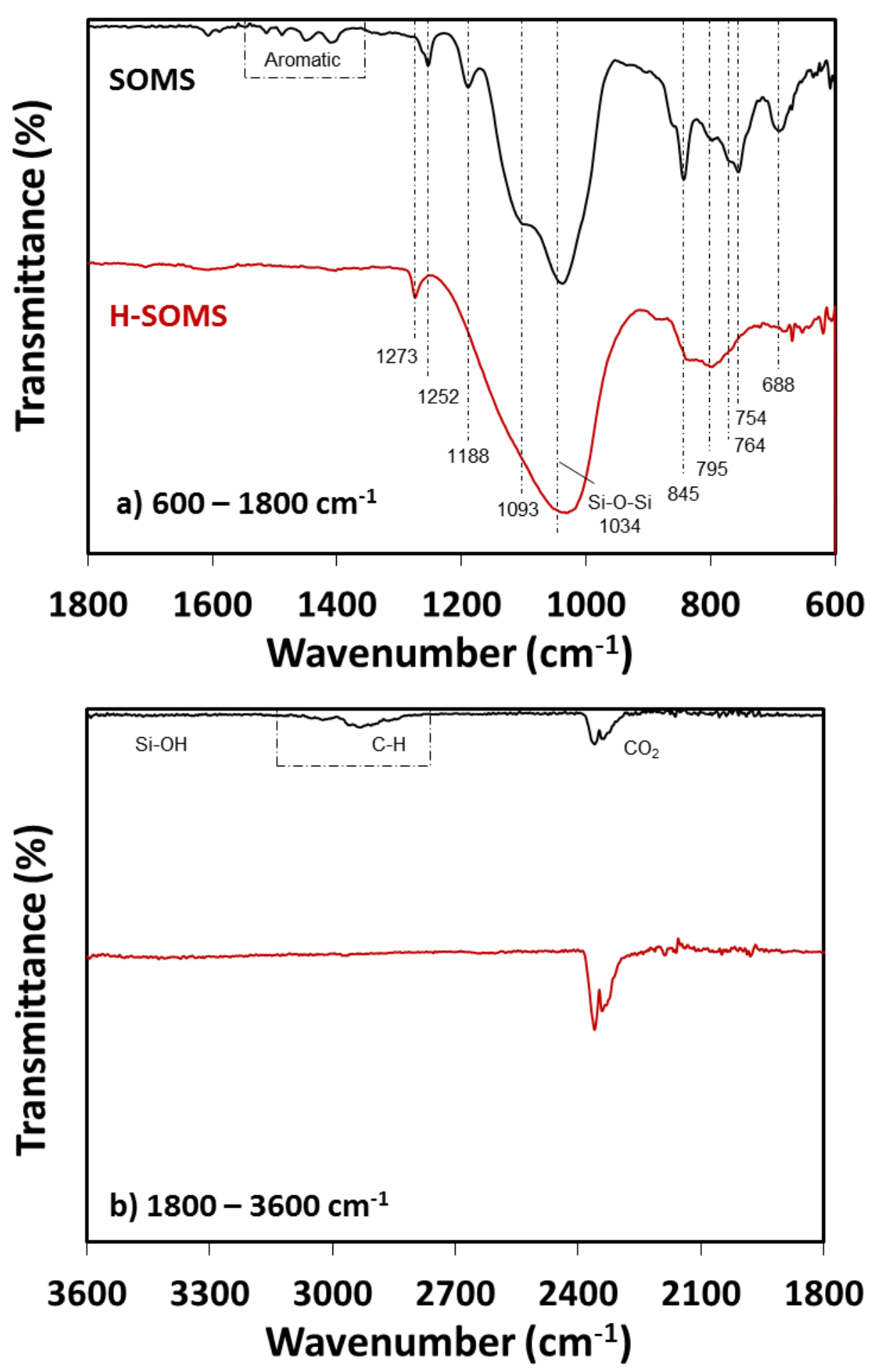

Figure 4. IR spectra for SOMS and H-SOMS in the range of a) $600-1800 \mathrm{~cm}^{-1}$ and b) 1800 $3600 \mathrm{~cm}^{-1}$ 


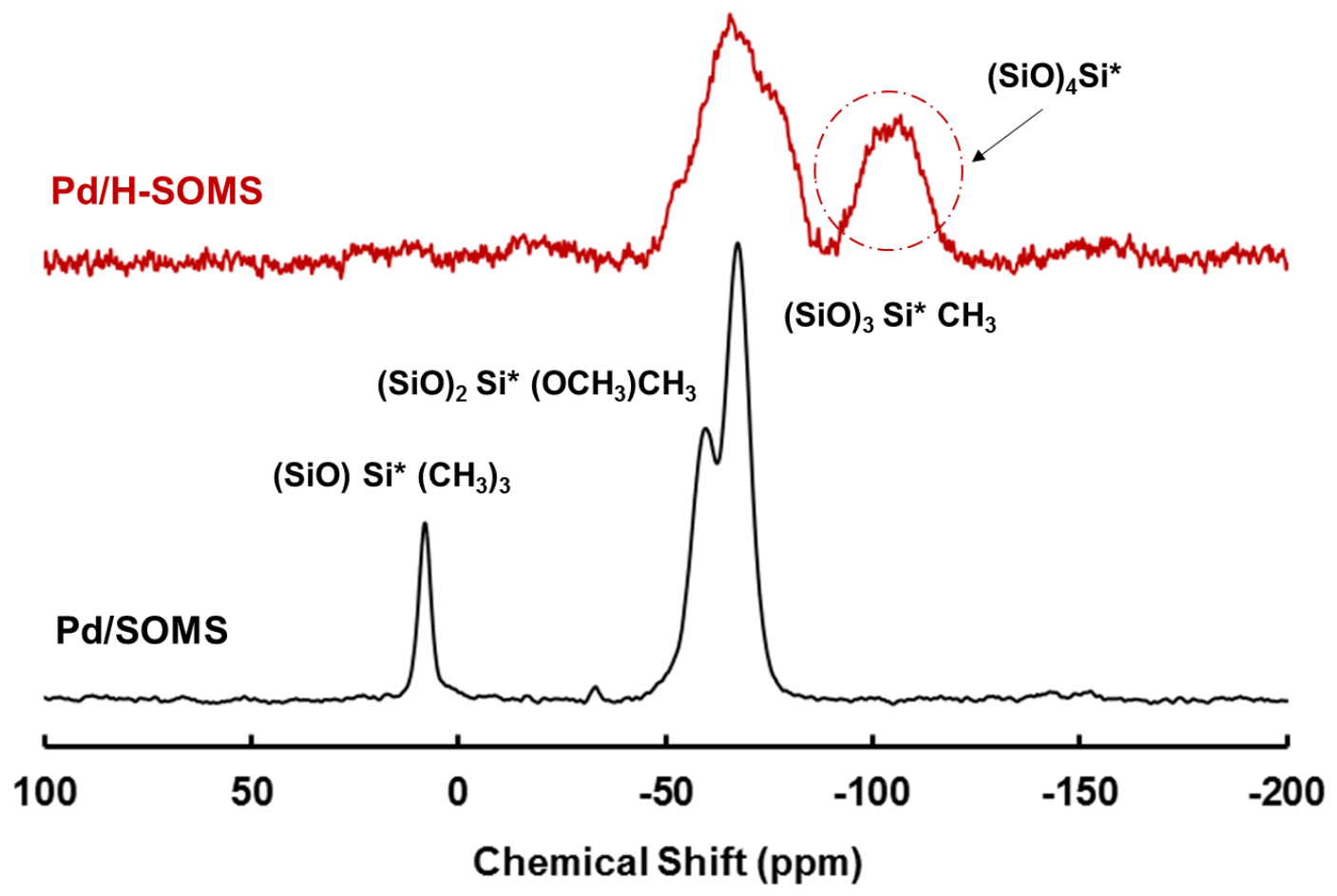

Figure 5. NMR spectra for Pd/SOMS and Pd/H-SOMS 

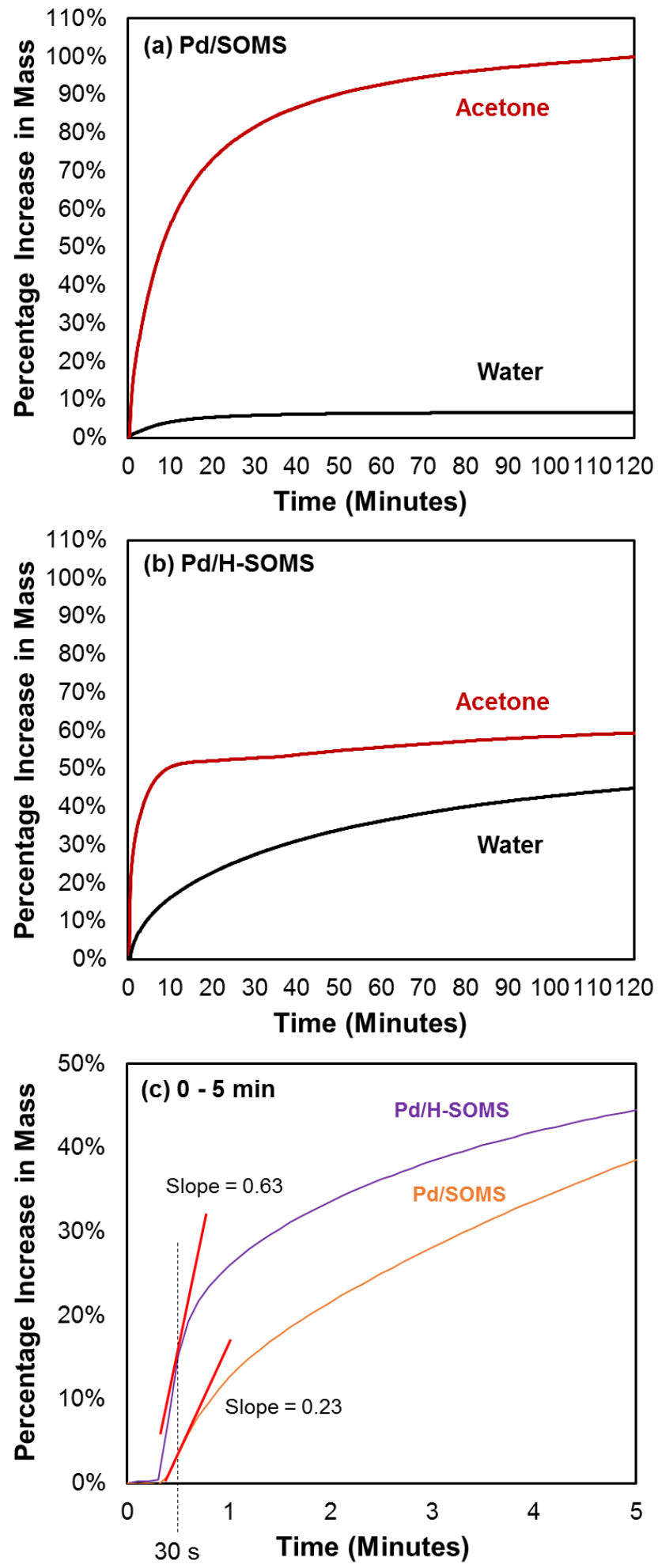

Figure 6. Absorption of acetone and water over (a) Pd/SOMS (b) Pd/H-SOMS, (c) comparison of absorption of acetone over Pd/SOMS and Pd/H-SOMS in the first $5 \mathrm{~min}$ 


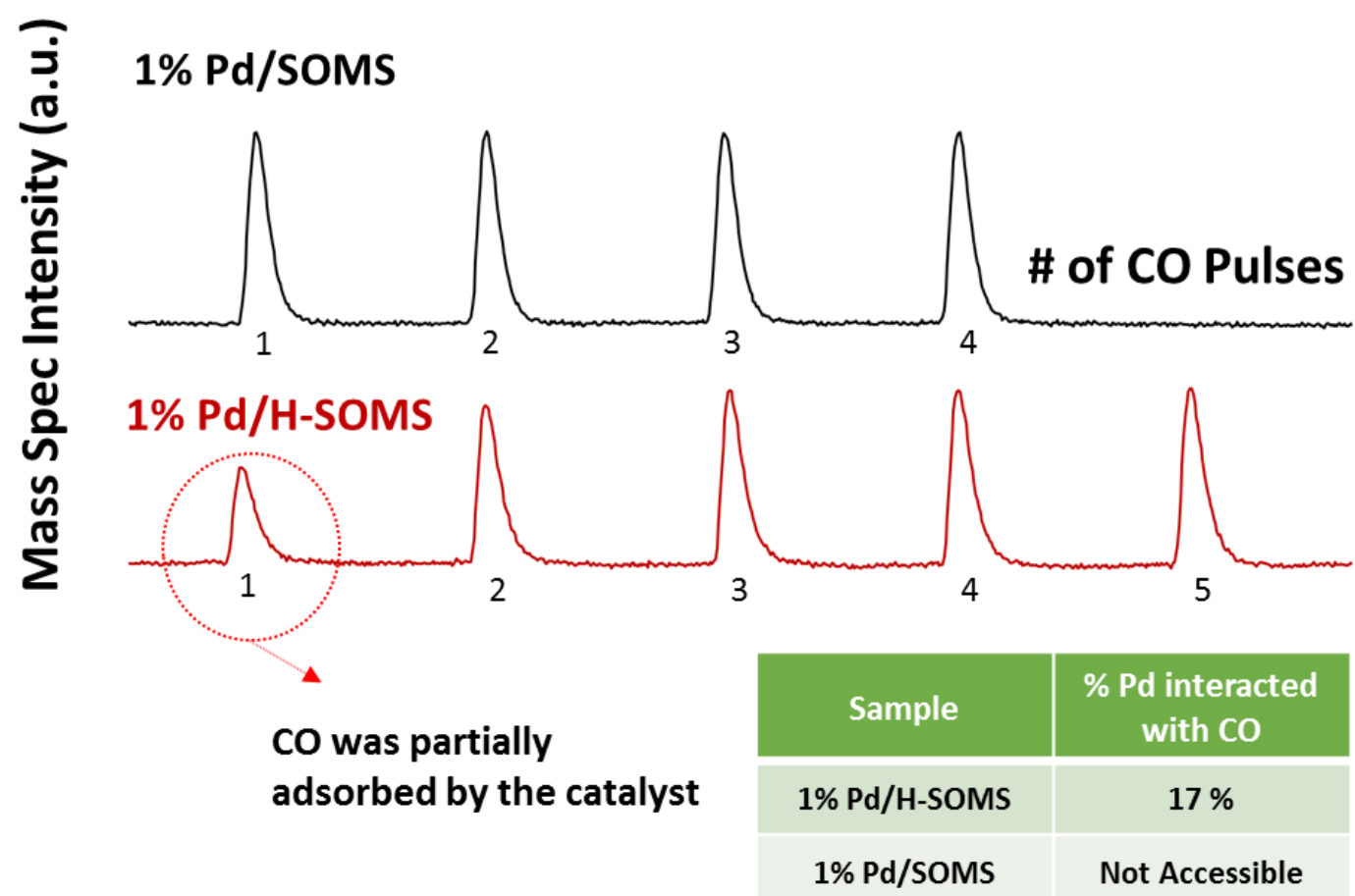

Figure 7. Results of CO Chemisorption 

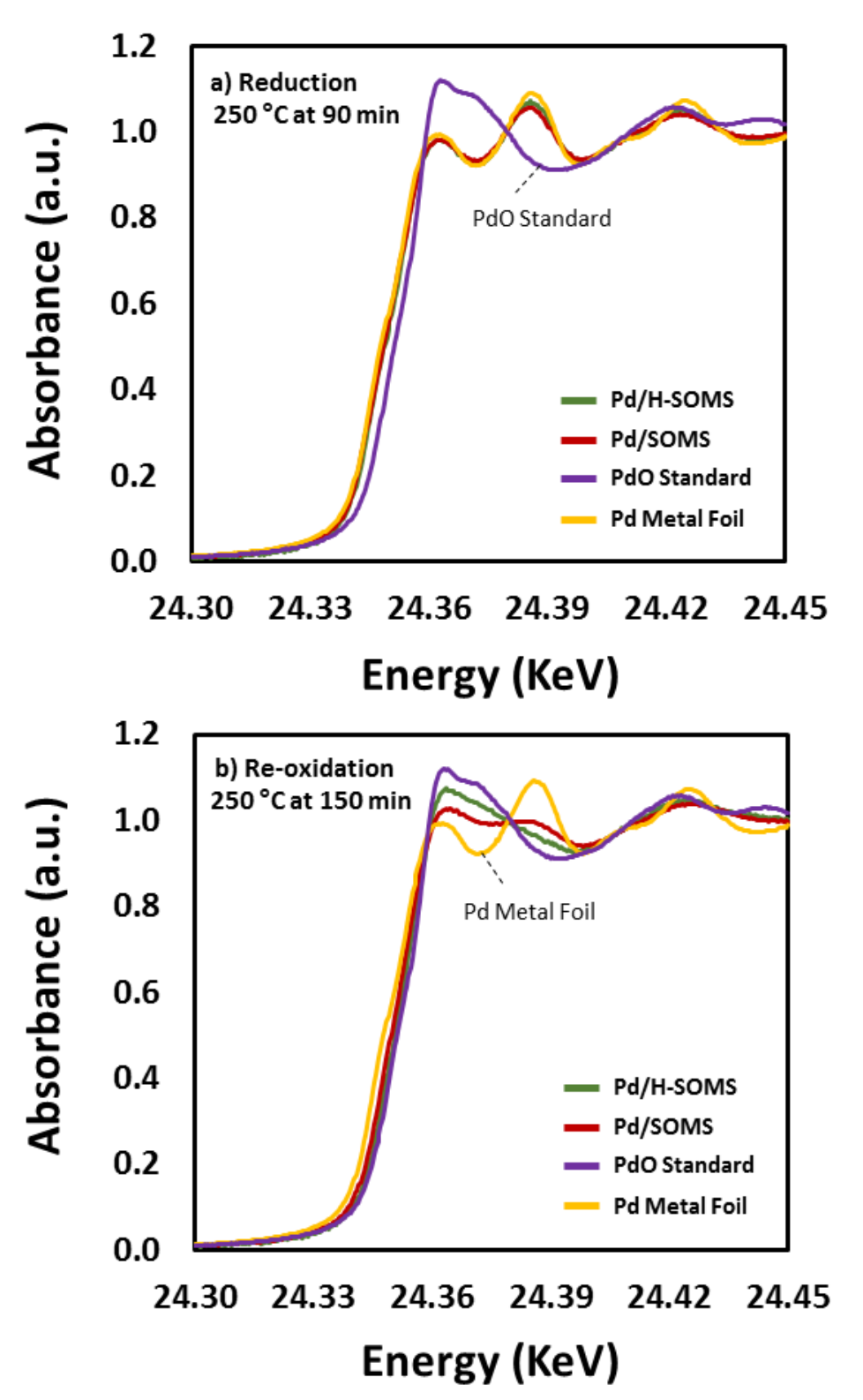

Figure 8. XANES spectra collected under reducing and oxidizing reaction conditions 


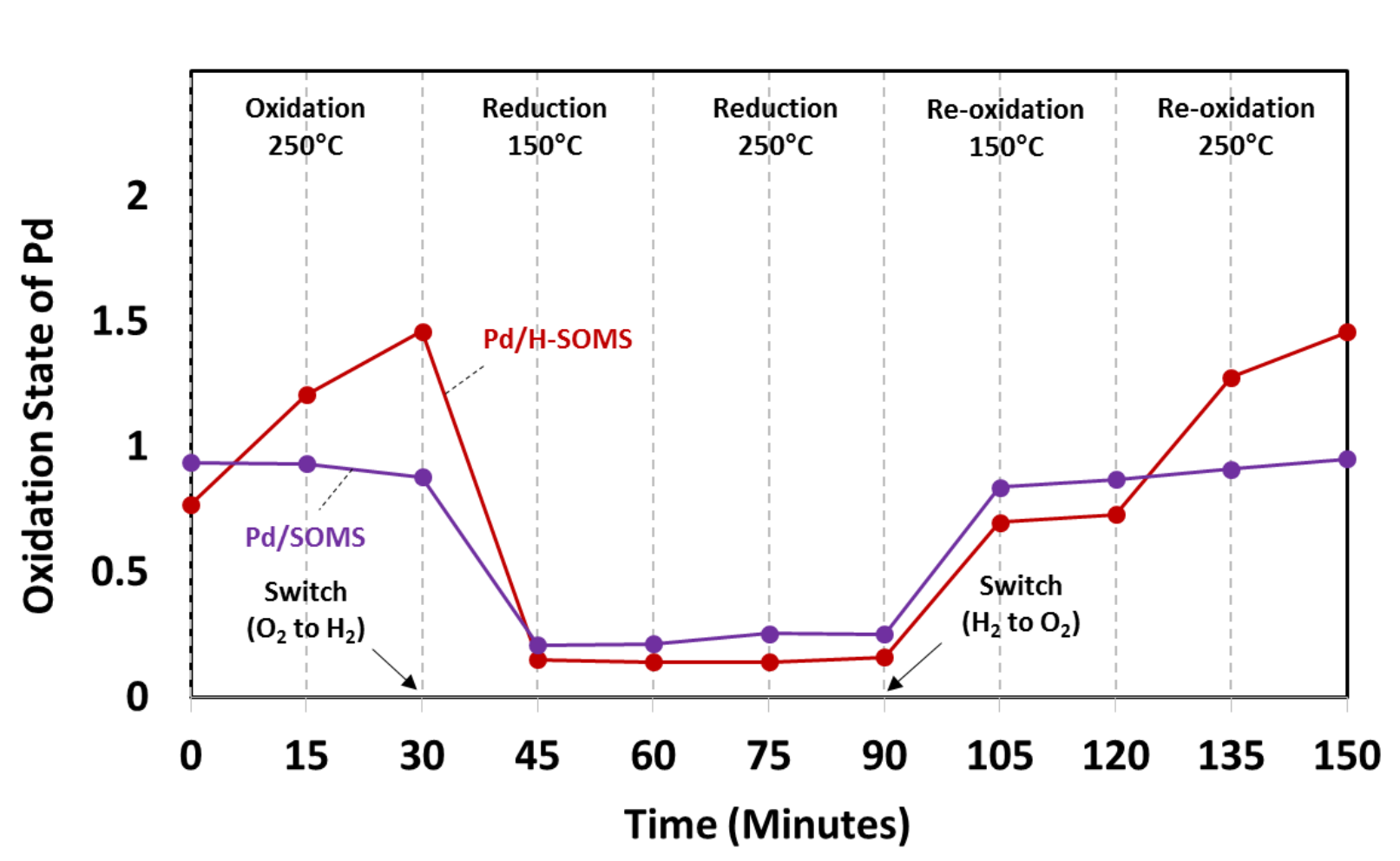

Figure 9. Change in oxidation states of $\mathrm{Pd}$ for $\mathrm{Pd} / \mathrm{SOMS}$ and $\mathrm{Pd} / \mathrm{H}-\mathrm{SOMS}$ in reducing and oxidizing reaction conditions 


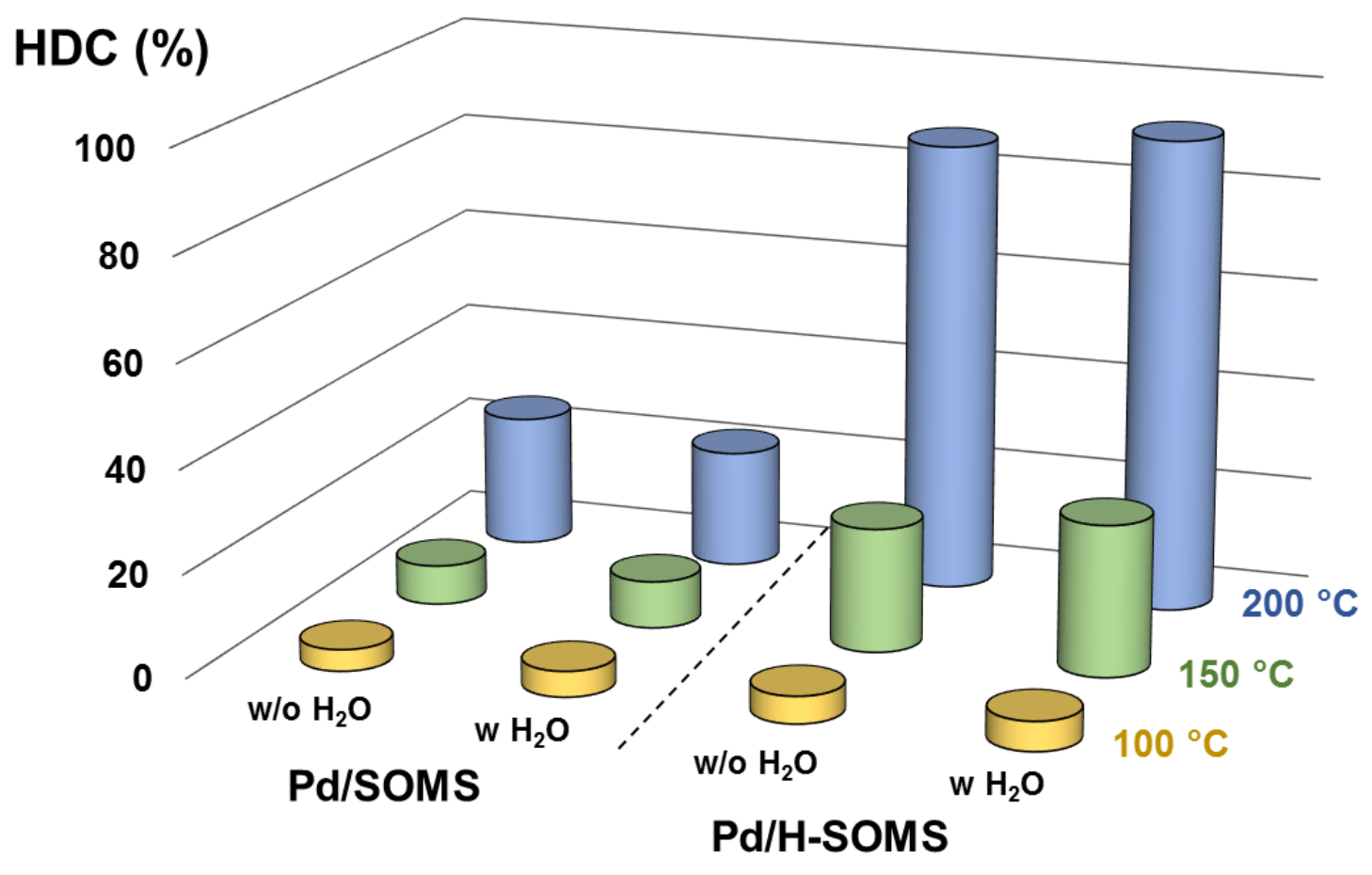

Figure 10. Comparison of percentage HDC of TCE in the presence/absence of water in the reactant stream for $\mathrm{Pd} / \mathrm{SOMS}$ and $\mathrm{Pd} / \mathrm{H}$-SOMS catalysts 


\section{Graphical Abstract}

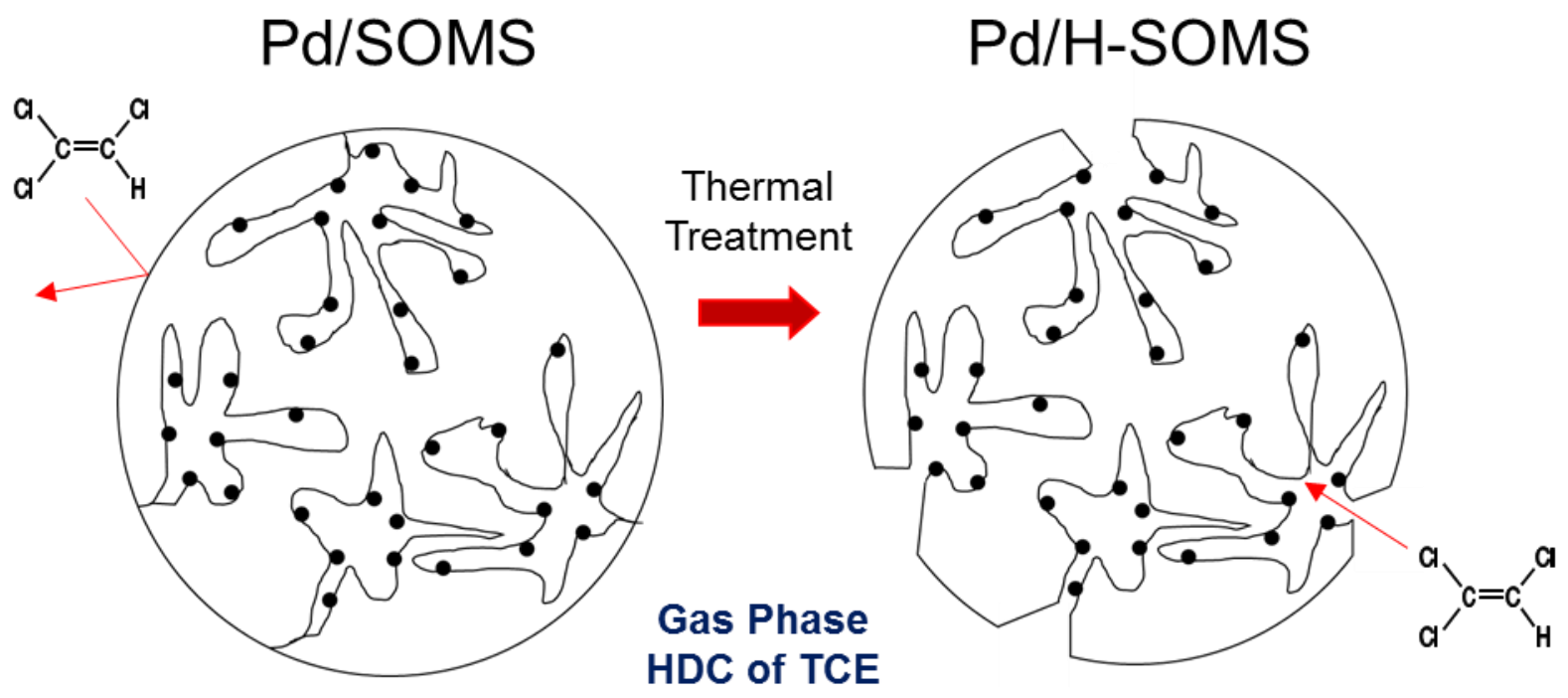

